\title{
Augmenting the Technology Acceptance Model with Trust Model for the initial adoption of a blockchain-based system
}

\author{
Ajay K Shrestha ${ }^{\text {Corresp., } 1}$, Julita Vassileva ${ }^{1}$, Sandhya Joshi ${ }^{2}$, Jennifer Just ${ }^{1}$ \\ ${ }^{1}$ Department of Computer Science, University of Saskatchewan, Saskatoon, Saskatchewan, Canada \\ 2 Unaffiliated, Saskatoon, Saskatchewan, Canada \\ Corresponding Author: Ajay K Shrestha \\ Email address: ajay.shrestha@usask.ca
}

Background. In the collaborative business environment, blockchain coupled with smart contract removes the reliance on a central system and offers data integrity which is crucial when the transacting parties rely on the shared data. The acceptance of such blockchain-based systems is necessary for the continued use of the services. Despite many extensive studies evaluating the performance of blockchainbased systems, few have focused on users' acceptance of real-life applications.

Objective. The main objective of this research is to evaluate the user acceptance of a real-life blockchain-based system (BBS) by observing various latent variables affecting the development of users' attitudes and intention to use the system. It also aims to uncover the dimensions and role of trust, security and privacy alongside the primary Technology Acceptance Model (TAM)-based predictors and their causal relationship with the users' behavior to adopt such BBS.

Methods. We tested the augmented TAM with Trust Model on a BBS that comprises two subsystems: a Shopping Cart System (SCS), a system oriented towards end-users and a Data Sharing System (DSS), a system oriented towards system administrators. We set research questions and hypotheses, and conducted online surveys by requesting each participant to respond to the questionnaire after using the respective system. The main study comprises two separate sub-studies: the first study was performed on SCS and the second on DSS. Furthermore, each study data comprises initial pre-test and post-test data scores. We analyzed the research model with partial least square structural equation modelling.

Results. The empirical study validates our research model and supports most of the research hypotheses. Based on our findings, we deduce that TAM-based predictors and trust constructs cannot be applied uniformly to BBS. Depending on the specifics of the BBS, the relationships between perceived trust antecedents and attitudes towards the system might change. For SCS, trust is the strongest determinant of attitudes towards system, while DSS has perceived privacy as the strongest determinant of attitudes towards system. Quality of system shows the strongest total effect on intention to use SCS, while perceived usefulness has the strongest total effect on intention to use DSS. Trust has a positive significant effect on users' attitudes towards both BSS, while security does not have any significant effect on users' attitudes toward BBS. In SCS, privacy positively affects trust, but security has no significant effect on trust, whereas, in DSS, both privacy and security have significant effects on trust. In both BBS, trust has a moderating effect on privacy that correlates with attitudes towards BBS, whereas security does not have any mediating role between privacy and attitudes towards BBS. Hence, we recommend that while developing BBS, particular attention should be paid to increasing user trust and perceived privacy. 


\section{Augmenting the Technology Acceptance Model with} 2 Trust Model for the initial adoption of a blockchain3 based system

Ajay Kumar Shrestha ${ }^{1}$, Julita Vassileva ${ }^{1}$, Sandhya Joshi ${ }^{2}$, Jennifer Just ${ }^{1}$

$8{ }^{1}$ Department of Computer Science, University of Saskatchewan, Saskatoon, Saskatchewan,

9 Canada

$10{ }^{2}$ Unaffiliated, Saskatoon, Saskatchewan, Canada

11

12 Corresponding Author:

13 Ajay Kumar Shrestha ${ }^{1}$

14101 Cumberland Ave S, Saskatoon, Saskatchewan, S7N 1L5, Canada

15 Email address: ajay.shrestha@usak.ca 


\section{Abstract}

43 Background. In the collaborative business environment, blockchain coupled with smart

44

contracts removes the reliance on a central system and offers data integrity which is crucial when the transacting parties rely on the shared data. The acceptance of such blockchain-based systems is necessary for the continued use of the services. Despite many extensive studies evaluating the performance of blockchain-based systems, few have focused on users' acceptance of real-life applications.

Objective. The main objective of this research is to evaluate the user acceptance of a real-life blockchain-based system (BBS) by observing various latent variables affecting the development of users' attitudes and intention to use the system. It also aims to uncover the dimensions and role of trust, security and privacy alongside the primary Technology Acceptance Model (TAM)based predictors and their causal relationship with the users' behavior to adopt such BBS. Methods. We tested the augmented TAM with Trust Model on a BBS that comprises two subsystems: a Shopping Cart System (SCS), a system oriented towards end-users and a Data Sharing System (DSS), a system oriented towards system administrators. We set research questions and hypotheses, and conducted online surveys by requesting each participant to respond to the questionnaire after using the respective system. The main study comprises two separate sub-studies: the first study was performed on SCS and the second on DSS. Furthermore, each study data comprises initial pre-test and post-test data scores. We analyzed the research model with partial least square structural equation modelling.

Results. The empirical study validates our research model and supports most of the research hypotheses. Based on our findings, we deduce that TAM-based predictors and trust constructs cannot be applied uniformly to BBS. Depending on the specifics of the BBS, the relationships between perceived trust antecedents and attitudes towards the system might change. For SCS, trust is the strongest determinant of attitudes towards system, while DSS has perceived privacy as the strongest determinant of attitudes towards system. Quality of system shows the strongest total effect on intention to use SCS, while perceived usefulness has the strongest total effect on intention to use DSS. Trust has a positive significant effect on users' attitudes towards both BBS, while security does not have any significant effect on users' attitudes toward BBS. In SCS, privacy positively affects trust, but security has no significant effect on trust, whereas, in DSS, both privacy and security have significant effects on trust. In both BBS, trust has a moderating effect on privacy that correlates with attitudes towards BBS, whereas security does not have any mediating role between privacy and attitudes towards BBS. Hence, we recommend that while developing BBS, particular attention should be paid to increasing user trust and perceived privacy.

\section{Introduction}

Blockchain technology has influenced significantly the financial world with its first application in the form of cryptocurrencies such as bitcoin (Nakamoto, 2008). After a decade long development phase, it has now exhibited high potential for a broader diffusion across many other 
82 industries such as healthcare, agriculture, tourism and research fields (Bullock \& Bannigan, 83 2016; Feng Tian, 2016; McGhin, Choo, Liu, \& He, 2019; Shrestha \& Vassileva, 2016, 2018b).

84 Blockchain technology is likely to disrupt many of the traditional centralized business models

85 because of its being decentralized, immutable, tamper-proof and transparent processes (Shrestha

86 \& Vassileva, 2018a; Swan, 2015). Many blockchain systems also support smart contracts that

87 encode the business logic into an autonomous self-executing piece of a program and are also

88 deployed on the blockchain. A Smart contract stores the rules which negotiate the terms of the

89 contract, automatically verifies the contract and executes the agreed terms whenever it is

90 triggered by the target collaborator or by the responsible process from another smart contract.

91 Blockchain coupled with smart contract technology removes the reliance on the central system

92 between the collaborators and the transacting parties (Shrestha, Deters, \& Vassileva, 2017).

93 However, blockchain is not a silver bullet that can be incorporated into any business use case. It

94 is particularly important to identify and conduct careful analysis and evaluation of different

95 factors affecting the collaborative business model that is built on the top of blockchain and smart

96 contracts technologies. Furthermore, (Prashanth Joshi, Han, \& Wang, 2018) argued in their

97 comprehensive survey that numerous privacy and security-related issues have risen while

98 adopting blockchain-based applications. (Kshetri, 2017), based on their findings, suggested that

99 although blockchain supports peer-to-peer security, the decentralized application itself is

100 vulnerable to security breaches and privacy infringements.

101

102

As suggested by (Cunningham, 1967), the evaluation process is crucial in studying the user

103

104 perception of the adoption of new information technology services. The Technology Acceptance

105

106

107

108

109

110

111

112

113

114 Model (TAM) proposed by (Davis, 1989) has been used widely in the literature to examine whether users understand the underlying technology and can competently use the services (Granić \& Marangunić, 2019). In many studies, researchers extend TAM by adding external constructs depending upon the contexts to explain the critical relationship between customers and their adoption of the new technology (Melas, Zampetakis, Dimopoulou, \& Moustakis, 2011). With the rapid development of the use cases of blockchain in recent years, a few studies have already been conducted considering the user acceptance of an abstract blockchain-based system (Folkinshteyn \& Lennon, 2016; Kern, 2018; Shin, 2019; Shrestha \& Vassileva, 2019a). Although numerous extensive systematic studies have been conducted on evaluating the performance of blockchain-based systems (Shrestha, Vassileva, \& Deters, 2020), to the best of our knowledge, no study has been conducted in the context of users' acceptance of real-life blockchain-based applications except for bitcoin as financial technology (Folkinshteyn \& Lennon, 2016). Previous works have evaluated user acceptance of the blockchain-based prototype system using an extended Technology Acceptance Model (TAM) in (Kern, 2018; Shrestha \& Vassileva, 2019a) and the trust model in (Shin, 2019). The previous studies suggest that the blockchain-based system will be accepted if it is perceived as trustworthy, convenient and useful (Kern, 2018; Shin, 2019). 
122 The major contribution of this study is that it expands the previous work by conducting a new

123

124

125

126

127

128

129

130

131

132

133

134

135

136

137

138

139

140

141

142

143

144

145

146

147

148

149

150

151

152

153

154

155

156

157

158

159

160 user study on a real-life blockchain-based system (BBS), described in (Shrestha, Joshi, \& Vassileva, 2020). This study presents the augmented TAM by incorporating additional constructs- Trust, Perceived Security and Perceived Privacy in technology adoption study and presents the total effect and mediation analyses. The findings are informative and potentially useful for designing new blockchain-based systems.

The BBS of our study is the general-purpose blockchain-based system that provides a solution to four important problems: private payment, ensuring privacy and user control, and incentives for sharing. This BBS was constructed for the online shopping cart which also allows customers to connect to the seller directly and share personal data without losing control and ownership of it. This BBS has two subsystems- a customer-specific shopping cart system (SCS), and a companyspecific data sharing system (DSS). SCS allows customers to set their data sharing preferences and deploy them via smart contracts, which gives customers full transparency over who accesses their data, when and for what purpose, specifies the purposes of data sharing, which kinds of data can be shared, which applications or companies can access their data and provide an incentive to them for sharing their data in terms of micropayment as stated in the contract. Similarly, DSS allows companies to check data integrity, get tamper-proof records and proof of existence of every transaction while sharing data in the consortium blockchain network. Therefore, the BBS used in the study is a very novel decentralized application that covers the aspects of both the customer and company. So, its in-depth analysis to examine all those factors of the Trust model and the TAM indicators that mostly affect the user acceptance of the BBS is crucial to provide an opportunity for a broad debate and perspective on potential uses of blockchain and smart contract technologies for the eCommerce domain along with other different important industries such as healthcare, agriculture, tourism and research fields.

Therefore, our current study is based on the user evaluation of the blockchain-based SCS and DSS, before and after using those sub-systems by the selected participants, using the validated constructs of the TAM and the Trust model. This new augmented model incorporates both classical TAM with perceived ease of use, perceived usefulness and quality of system, and Trust model with security and privacy variables, and it can be applied to evaluate the acceptance of the general blockchain- and smart contracts-based systems. The present study, using the partial least square structural equation modeling on augmented TAM, hypothesizes and validates various causal relationships to observe the statistical significance between the constructs of interest and intention to use the BBS.

The remainder of the paper is organized as follows: Section II provides some background of the BBS and augmented TAM model. Section III presents the research models and hypotheses. The research methodology with measurement and structural models is presented in section IV. 
161 Section $\mathrm{V}$ focuses on the brief analysis of the results and section VI provides the discussion. The

162

163

164

165

166

167

168

169

170

171

172

173

174

175

176

177

178

179

180

181

182

183

184

185

186

187

188

189

190

191

192

193

194

195

196

197

198

limitation of the study is presented in section VII. Finally, section VIII concludes the paper.

\section{Background}

This section provides background information about the Blockchain-Based System used in the study described in this paper, the Technology Acceptance Model, and the models of Privacy, Security and Trust used to predict software systems' adoption by users.

\section{Blockchain-Based System (BBS)}

The term BBS for a general blockchain-based system was initially used in (Jun, 2018) without any detailed explanation. BBS in our study represents the blockchain-based service that we have developed with an engineering-oriented approach to address trust-aware business processes in an e-commerce domain, in the context of an online shopping cart system (Shrestha, Joshi, et al., 2020). The requirements for the BBS are:

- To enable companies to increase trust in their products and supply chains.

- To offer direct payment with native Ethereum tokens thereby enabling privacy and confidentiality.

- To create proof of the existence of every transaction.

- To give the users full transparency over who accesses their data, when and for what purpose.

- To enable companies to share customers' data among others in the consortium network.

- To provide incentives to customers in real-time for sharing their data.

This BBS has a 3-tier architecture (Fernandez, Fonoage, VanHilst, \& Marta, 2008) employing Spring Boot ${ }^{1}$ and React $^{2}$ as the main building technologies. The system uses permissioned MultiChain as a solution to both on-chain and off-chain data storage, encryption, hashing and tracking of data, together with Ethereum. Ethereum is used for access control and enabling transactions with ethers that allow users to shop online with all the transactions stored in the blockchain and get incentives for permitting to share their data as they specify in the smart contracts. Figure 1 presents the interaction among the customer (data provider) and other ecommerce companies/apps (data consumers) of the BBS. The system comprises two subsystems: Shopping Cart System (SCS) and Data Sharing System (DSS). SCS is used in the online shopping cart enterprise. It has a payment mechanism supporting cryptocurrency, ether and manages the mutual agreement between customers and enterprise through smart contracts. SCS automatically registers the immutable timestamped information about the transactions that acts as proof of existence and can be useful to settle any disputes between the stakeholders in the future. Moreover, SCS deploys smart contracts that allow customers to provide their data sharing preferences on a template form without needing them to write the code for the smart contracts. The smart contracts support users in the following ways (Shrestha \& Vassileva, 2019b):

${ }^{1} \mathrm{https}: / /$ spring.io/projects/spring-boot

2 https://reactjs.org/ 
199

200

201

202

203

204

205

206

207

208

209

210

211

212

213

214

215

216

217

218

219

220

221

222

223

224

225

226

227

228

229

230

231

232

233

234

235

236

237

- Give users full transparency over who accesses their data, when and for what purpose.

- Allow users to specify the purposes of data sharing, which kinds of data can be shared, and which applications or companies can access the data.

- Provide an incentive to users for sharing their data (in terms of payment for the use of the data by applications, as specified by the contracts).

DSS is used for sharing user data among the companies, that provide the shopping cart system to the customers. DSS allows enterprises to form a consortium blockchain network in the MultiChain environment so that user data are only shared with the particular node, that has been given the data access permission, as defined in the smart contracts when deployed by customers on SCS. DSS offers tamper-proof encrypted data storage, publication and provenance mechanisms with a transparency of the event log mechanism in collaborative processes where different enterprises use published/shared data.

\section{Augmented Technology Acceptance Model}

The classical Technology Acceptance Model (TAM) as shown in Fig. 2 was based on the Theory of Reasoned Action (Fishbein \& Ajzen, 1975) in social psychology, which claims that behavioral intention is a strong indicator of actual behavior. The TAM has been used as a conceptual framework in many studies of the potential users' behavioral intention to use a particular technology. The behavioral intention is defined as "the degree to which a person has formulated conscious plans to perform or not perform some specified future behavior" (Warshaw \& Davis, 1985). The classical TAM focuses on using technology, where perceived ease of use (PEOU) and perceived usefulness (PU) are two design attributes or antecedent to influence user acceptance behavior. PEOU is defined as the degree to which a person believes that using a particular system would be free of effort. PU is the degree to which a person believes that using a particular system would enhance his or her job performance. TAM hypothesizes that the actual use of the system is determined by behavioral intention to use (ITU), which is the degree to which a person has behavioral intention to adopt the technology. ITU is in turn influenced by the user's attitude towards use, perceived usefulness and perceived ease of use of the system.

Attitude towards use is the degree of belief to which a person uses the system as guided by valuations (Shin, 2019; Shin, 2017).

TAM is widely used to understand how users come to accept and use information technology. However, there is no existing literature on using TAM in the context of real-life blockchains and smart contracts-based applications, indicating a significant gap in the knowledge. To fill this research gap in the existing literature, this study applies the augmented TAM with trust model to the BBS that we implemented, with participants who actually used the system before answering the survey questionnaires. Our study also uncovers the individual mediating effects of trust, security and perceived usefulness. 
238 In classical TAM, the main design constructs such as perceived ease of use and perceived 239 usefulness have shown significant influence on the behavioral intention of the user to adopt the 240 information systems (Davis, 1989), and the latest study by (Shin, 2019) shows the necessity of 241 considering the Trust-Security-Privacy factors in the decision model of the blockchain-based242 solution adoption. So, we adopted the partial least square structural equation modeling (PLS243 SEM) analyses on the augmented TAM as it is a useful technique to estimate complex cause244 effect relationship models with latent variables and we aimed to model the latent constructs 245 under conditions of non-normality and small sample sizes (Kwong \& Wong, 2013).

246

247

248

249

250

251

252

253

254

255

256

257

258

259

260

261

262

263

264

265

266

267

268

269

270

271

272

273

274

275

276

277

Many researchers often extend TAM by adding external constructs because classical TAM often does not capture many key factors specific to the context of the technology (Melas et al., 2011). Quality of system (QOS) (Koh, Prybutok, \& Ryan, 2010), trust (T) (Wu \& Chen, 2005), behavioral control (Bhattacherjee, 2000) are some of the constructs that have been added as influential variables to user acceptance of the information technology and are therefore inevitable for evaluating a novel system, BBS as in this current study. Although in the software engineering domain, security and privacy are regarded as part of QOS, in this study, we have presented perceived security and perceived privacy as separate constructs. (DeLone \& McLean, 1992) refers to QOS as the technical details of the system interface and system's quality that produces output response such that the technology attributes singularly or jointly influence user satisfaction. Hence, it is assumed that the QOS affects user satisfaction and that directly or indirectly through PU, affects users' intention to use the system (DeLone \& McLean, 1992; Shrestha \& Vassileva, 2019a).

Moreover, perceived privacy and perceived security have critical roles in the acceptance of the technologies as the prior research suggest they have a significant effect on users' attitudes that positively influence their intention to use the technologies (Amin \& Ramayah, 2010; Roca, García, \& de la Vega, 2009; Shin, 2010).

\section{Multidimensionality of Privacy}

Privacy is defined as the right to be let alone (Warren \& Brandeis, 1890). Furthermore, privacy has been considered as the right to prevent the disclosure of personal information to others (Westin, 1968). Later, privacy has been known to be not just unidimensional (Burgoon et al., 1989; DeCew, 1997)) as it includes informational privacy along with accessibility privacy, physical privacy and expressive privacy.

- Informational privacy - "how, when, and to what extent information about the self will be released to another person" (Burgoon et al., 1989; DeCew, 1997), e.g. the user is asked for too much personal information while using online services.

- Accessibility privacy- "acquisition or attempted acquisition of information that involves gaining access to an individual" (DeCew, 1997), e.g. the user's contact (address, phone or email) information might be left in the old system.

Peer) Comput. Sci. reviewing PDF | (CS-2020:10:53488:1:1:NEW 25 Mar 2021) 
278

279

280

281

282

283

284

285

286

287

288

289

290

291

292

293

294

295

296

297

298

299

300

301

302

303

304

305

306

307

308

309

310

311

312

313

314

315

316

317

- Physical privacy- "the degree to which a person is physically accessible to others" (Burgoon et al., 1989) e.g. viewing user screen in an unauthorized way.

- Expressive privacy- "protects a realm for expressing one's self-identity or personhood through speech or activity"(DeCew, 1997). It restricts extrinsic social control over choices and improves intrinsic control over self-expression, e.g., user data may be inappropriately forwarded to others.

(Introna \& Pouloudi, 1999) developed a framework of principles for the first time to study privacy concerns while exploring the interrelations of interests and values for various stakeholders. The study has identified that different users have distinct levels of concern about their privacy. (Smith, Milberg, \& Burke, 1996) developed a scale for the concern for privacy that measured unidimensional aspects of privacy such as collection, errors, secondary use, and unauthorized access to information factors. (Malhotra, Kim, \& Agarwal, 2004) also presented a model to consider multiple aspects of privacy such as identifying attitudes towards the collection of personally identifiable information, control over personal information and awareness of privacy practices of companies gathering personal information. However, all these studies just focused on the informational privacy, so the scales to measure privacy were also based on a unidimensional approach and were not even validated. Furthermore, the issue regarding the benefit to giving up privacy such as offering personalization, enhanced security etc. was not addressed by those studies.

Hence, to address the multidimensionality of privacy, it is particularly important to consider privacy-related behaviors while studying privacy concerns and user attitudes towards privacy in BBS. The constructs presented in a study by (Buchanan, Paine, Joinson, \& Reips, 2007) are validated and considered both privacy concerns and user behavior models. The behavioral items include general caution and technical protection of privacy. Attitudinal item includes privacy concern. The authors found that privacy concern correlates significantly with a general caution, but not significantly with the technical protection factor. Furthermore, perceived privacy, which is the attitudinal privacy or privacy concern undoubtedly plays a critical role in user accepting technologies (Hoffman, Novak, \& Peralta, 1999; Poon, 2008)). It sheds light on the possibility of unauthorized use and access to the personal and financial information of the users by the companies that they are intending to use the service of (Dwyer, Hiltz, \& Passerini, 2007).

\section{Perceived Security}

Perceived security is the degree to which a user believes that the online service has no predisposition to risk (Yenisey, Ozok, \& Salvendy, 2005). The protected financial and personal information may get compromised by theft and fraudulent activities leading to vulnerability on the internet. Because of this, a sense of security becomes a major concern for the customers to handout their details on the network (Gefen, 2000; Shrestha, 2014; Wang, Lee, \& Wang, 1998). Perceived security here does not only mean technical security but the user's subjective feeling of

Peer] Comput. Sci. reviewing PDF | (CS-2020:10:53488:1:1:NEW 25 Mar 2021) 
318 being secured in the network (Roca et al., 2009). Authors (Linck, Pousttchi, \& Wiedemann, 319 2006) have argued that a lack of subjective security in the user's mind will create hesitation to 320 use systems.

321

322

323

324

325

326

327

328

329

330

331

332

333

334

335

336

337

338

339

340

341

342

343

344

345

346

347

348

349

350

351

352

353

354

355

356

357

\section{Trust as Mediating Factor}

Trust is an important contributing factor for users to do a certain task that can make them vulnerable and yet hope the service provider on the other end to fully comply with the set of protocols to complete a transaction (Dwyer et al., 2007) and eventually develop a new relationship (Coppola, Hiltz, \& Rotter, 2004; Jarvenpaa \& Leidner, 1999; Piccoli \& Ives, 2003). In a virtual environment, as the users do not have any control over the outcome of their actions, trust becomes one of the prime factors for them to ground some firm belief in the reliability to engage with the other party (Hoffman et al., 1999). In e-commerce, when information is disclosed, users tend to trust more the service provider (Metzger, 2004) resulting in users being free of doubts and are more likely to engage with the other party (Hoffman et al., 1999). Research has shown that trust has a positive significant impact on attitude and intentions to use systems (Papadopoulou, 2007). With greater trust, users question less the authenticity of online services.

The user acceptance behavioral model, as presented by (Rios, Fernandez-Gago, \& Lopez, 2017; Shin, 2010) for theoretical social network services, is also useful for conceptualizing the role of perceived security, perceived privacy (privacy concern from attitudinal privacy) on user trust. Their findings revealed that perceived security has a moderating effect on perceived privacy that correlates significantly with trust the user can have on the system.

\section{Related Work}

Numerous studies have been conducted to examine the factors that determine the acceptance of information technology in the context of an extended TAM and Trust model. We cover a crosssection of those studies that are related to our work.

To the best of our knowledge, (Folkinshteyn \& Lennon, 2016) conducted a very first user study with TAM in the context of the adoption of bitcoin as financial technology. Their findings revealed both positive and negative factors associated with the acceptance of bitcoin, the first real-life application of blockchain technology. They have also argued that the cryptocurrency offers borderless and efficient transactions with significant positive factors in PEOU and PU, giving users full control over their currency, however it is also extremely volatile with not being lenient of security breaches or errors (Folkinshteyn \& Lennon, 2016). So, it has both risks and benefits that affect the overall adoption of the cryptocurrency. Their findings also suggested exploring other aspects beyond TAM variables to consider the underlying risk and trustworthiness constructs associated with the blockchain-based applications. Previous research by (Kern, 2018; Shin, 2019) on an abstract blockchain-based application model suggested that 
358

359

360

361

362

363

364

365

366

367

368

369

370

371

372

373

374

375

376

377

378

379

380

381

382

383

384

385

386

387

388

389

390

391

392

393

394

395

396

397

the blockchain-based system can be accepted if it has enough trust to sustain and is perceived as convenient and useful in the highly competitive market. Almost all of the existing research so far is limited to the blockchain-based prototype system using an extended TAM (Kern, 2018; Shrestha \& Vassileva, 2019a) and Trust model (Shin, 2019). Our current study extends the research contribution of the prior study (Shrestha \& Vassileva, 2019a) by conducting a new user study on the real-life blockchain-based system, BBS (Shrestha et al., 2020).

Gefen et al. have previously explored a mixed model with TAM and Trust model to study the adoption of the on-line shopping setting (Gefen, Karahanna, \& Straub, 2003). Their model presented the use of the on-line system into both system attributes such as perceived usefulness and perceived ease of use and trust in e-vendors. Their model resulted in the integrative indication of the TAM and Trust constructs as good predictors for the output response, which was the behavioral intention to use the online shopping system. Therefore, the current study adopts a similar model and presents it as augmented TAM which comprises an extended TAM and Trust model.

As online activities such as online shopping generate a plethora of real-time transactions of all kinds of assets and information, they are prone to security and privacy-related risks (Roca et al., 2009). A privacy issue mostly occurs with unwarranted access to the users' personal data, but that does not necessarily involve security breaches, which can happen with poor access control mechanisms in the system allowing malicious actors to control the system. However, both breaches are critical issues and they often exist together on the online services where users typically feel hesitant to provide private information over the internet (Hoffman et al., 1999). (Shin, 2010) previously explored the statistical significance of security and privacy in the acceptance of social networking sites. Later, (Shin, 2019) presented the role and dimension of digital trust in the emerging blockchain context, where (Siegel \& Sarma, 2019) has argued that it has not been investigated how privacy/security factors affect user's behavioral cognitive process of accepting the blockchain-based systems. This study, in addition to previous TAM validated constructs, explores the users' perception towards the security and privacy aspect of the BBS and their influence on intention to use the BBS by using the moderating effects of trust on attitudes towards system. Besides, the current research aims to answer the following research questions when exploring the relationship between different indicators of the augmented TAM with the trust model:

- RQ1: Which of the design attributes is/are the strongest antecedents of the attitudes towards BBS?

- RQ2: Which of the design attributes is/are the strongest antecedents of the intention to use BBS?

- RQ3: Is the influence of privacy on attitudes towards BBS mediated by both security and/or trust?

- RQ4: Is the influence of security on attitudes towards BBS mediated by trust? 
398

399

400

401

402

403

404

405

406

407

408

409

410

411

412

413

414

415

416

417

418

419

420

421

422

423

424

425

426

427

428

429

430

431

432

433

434

435

436

- RQ5: Is the influence of ease of use/quality of system on intention to use BBS mediated by perceived usefulness?

\section{Research Model and Hypotheses}

Figure 3 presents the structural model with the main constructs and their associated structural paths. Fourteen research hypotheses are thus constructed for our research model based on the findings of the literature review presented in the previous section.

Perceived Usefulness and Perceived Ease of Use (Davis, 1989; Davis, Bagozzi, \& Warshaw, 1992)

H1: Perceived ease of use significantly influences the perceived usefulness of BBS.

$\mathrm{H} 2$ : Perceived ease of use significantly influences the intention to use BBS.

H3: Perceived usefulness significantly influences the intention to use BBS.

Quality of System (Koh et al., 2010)

H4: Quality of system significantly influences the perceived usefulness of BBS.

H5: Quality of system significantly influences the intention to use BBS.

Attitude Towards BBS (Shin, 2017)

H6. Attitude towards BBS significantly influences the intention to use BBS.

Trust (Dennis, Robert, Curtis, Kowalczyk, \& Hasty, 2012); (Jian, Bisantz, \& Drury, 2000)

H7. Trust positively affects users' attitudes toward BBS.

Perceived Privacy (Buchanan et al., 2007)

H8. Perceived privacy has a positive effect on the users' trust in BBS.

H9. Perceived privacy has a positive effect on the users' attitudes toward BBS.

H10. Perceived privacy positively or negatively affects users' perceived security.

H11: Privacy concern positively affects users' behavior on general caution.

H12: Privacy concern positively affects users' behavior on technical protection.

Perceived Security (Shin, 2010)

H13. Perceived security positively affects users' trust in BBS.

H14. Perceived security positively affects users' attitude toward BBS.

The main study comprises two separate sub-studies: the first study was performed on the SCS and the second on the DSS. Furthermore, each study data comprises pre-test and post-test data scores. The pre-test defines the data collected from participants before they use the system, whereas post-test data is collected after participants use the system. 
437 The pretest study can be considered as the study associated with the prototype model. Since, the 438 present study follows the previous research work from (Shrestha \& Vassileva, 2019a), the

439

440

441

442

443

444

\section{5}

446

447

448

449

450

451

452

453

454

455

456

457

458

459

460

461

462

463

464

465

466

467

468

469

470

471

472

473

474

475

476 pretests for the current study do not include the constructs from classical TAM as they were already evaluated in the previous study. So, the pretests of the current study do not present data for hypotheses H1 - H6. The post-tests for both SCS and DSS do not have behavioral privacygeneral caution and-technical protection constructs as they are only evaluated once, during the pre-test. So, the post-test data do not test hypotheses H11 - H12.

\section{Materials \& Methods}

The present study was approved with delegated review by the University of Saskatchewan Behavioural Research Ethics Board (Beh-REB). The approval with reference number Beh \# ID2106 was given for behavioural application/amendment form, consent form and survey questionnaire. We first conducted a pilot study with 14 participants from the Multi-User Adaptive Distributed Mobile and Ubiquitous Computing (MADMUC) Lab and quantitative research experts at the University of Saskatchewan to evaluate the feasibility, duration and improve upon the study design of our research approach. The participants in the pilot study provided feedback with their opinion of the survey in general. Based on the pilot test outcomes and the review of quantitative research experts, the final survey questionnaires were modified and restructured, and then the research model was empirically tested by collecting survey data. The design of the research instrument, sample organizations and sample demographics are described below.

\section{Research Instrument Design}

We conducted online surveys through SurveyMonkey by requesting each participant to respond to the questionnaire on different constructs. The survey instrument is based on constructs validated in prior studies by (Buchanan et al., 2007; Davis, 1989; Davis et al., 1992; Dennis et al., 2012; Jian et al., 2000; Koh et al., 2010; D. H. Shin, 2010, 2017) and adapted in the context of our research model. The instrument consists of 6 items for perceived ease of use, 6 items for perceived usefulness, 4 items for quality of system, 3 items for perceived enjoyment, 4 items for intention to use, 3 items for perceived security, 9 items for trust, 4 items for attitudinal privacy (perceived privacy), 4 items for behavioral privacy-general caution, 4 items for behavioral privacy-technical protection and 3 items for attitude towards BBS. For our later analysis, we did not consider data related to perceived enjoyment. All the respective items (questions) in the constructs are provided as supplemental files. We measured the responses to the items on a 7scale Likert scale from $1=$ strongly disagree to 7 = strongly agree.

\section{Sample Organizations}

We recruited participants through the website announcement on the University of Saskatchewan's PAWS homepage and on the social networking site, LinkedIn. Participation was entirely voluntary. The participants had to read and accept the consent form to participate in 
477 the study. No real identities and email addresses were collected during the data-gathering phase

478 in the surveys. The consent for participation was obtained via an implied consent form. By

479 completing and submitting the questionnaire, participants' free and informed consent was

480 implied and indicated that they understood the conditions of participation in the study spelled out 481 in the consent form.

482 To contextualize the surveys for SCS, we provided participants at the beginning of the pre-test 483 survey questionnaire (presented as the supplemental file in Article S1) with a video about a brief 484 description of blockchain technology and BBS. The inclusion criteria for the SCS survey was 485 that any individual with knowledge about the internet could participate. After participants 486 completed the pre-test survey, we presented them with another video about using the SCS and 487 hosted a remote session allowing them to use the SCS for fifteen minutes. We did not record but 488 noted down their comments and confusion during their interaction with the system. Thereafter, 489 we presented them with a post-test survey questionnaire (presented as a supplemental file in 490 Article S2) to measure different constructs of our Augmented TAM with Trust model.

491 Similarly, we conducted the pre-test and post-test surveys for the DSS part as well. The post-test 492 survey questionnaire for DSS is presented as a supplemental file in Article S3. Each participant 493 in the DSS survey was also asked to use the DSS remotely for fifteen minutes. The inclusion criteria for the DSS survey was that the participants should be from a technical (computer science or engineering) background because the DSS includes technical aspects that only the software developer or system administrator could understand better. Most of the participants

497

498

499

500

501

502

503

504

505

506

507

508

509

510

511

512

513

514

515

516 completing DSS surveys also took part in the SCS surveys.

\section{Participants Demographics}

A total of 66 participants took part in the SCS study and 53 participated in the DSS study. However, upon cleaning, 63 valid responses for SCS and 50 for DSS were left for the analysis. We used a partial least square nonparametric bootstrapping procedure to test the statistical significance with 5000 subsamples (Hair, J. F., Hult, G. T. M., Ringle, C. M., \& Sarstedt, 2013) so that the resampling process would create subsamples with observations randomly drawn from the original set of data. For the study, we based our survey by collecting data from the participants who understood at least something about the blockchain and smart contract technologies after watching the video that we prepared on blockchain technology and BBS. The mean score suggests that for SCS, 79\% of participants have basic knowledge and 19\% have advanced knowledge of blockchain technology; whereas for DSS, 68\% of participants have basic knowledge and $28 \%$ have advanced knowledge of blockchain technology. Table 1 highlights the demographics of the participants.

\section{Results}

We used SPSS version 26 to process the collected data with descriptive statistics. We analyzed the research model with structural equation modelling using smartPLS (Partial Least Squares). PLS is a well-established technique for estimating path coefficients in structural models and has 
517 been widely used in research studies to model latent constructs under conditions of non518 normality and small to medium sample sizes (Kwong \& Wong, 2013). The structural equation 519 model (SEM) as suggested by (Hair, J. F., Hult, G. T. M., Ringle, C. M., \& Sarstedt, 2013) 520 includes the testing of the measurement models (exploratory factor analysis, internal consistency, 521 convergent validity, divergent validity, Dillon-Goldstein's rho) and the structural models 522 (regression analysis). We started by fitting the measurement models to the data and later we 523 tested the underlying structural models.

524

525 We applied the path weighting structural model scheme in smartPLS (Kwong \& Wong, 2013),

526 which provides the highest $\mathrm{R}^{2}$ value for endogenous or dependent latent variables. The purpose

527

528 of PLS regression is to combine features from principal component analysis (PCA) and multiple

529 regression (Roca et al., 2009). PLS-SEM is applicable for all kinds of PLS path model

530

531

532

533

534

535

536

537

538

539

540

541

542

543

544

545

546

547

548

549

550

551

552

553

554

555

specifications and estimations. We first used 300 maximum iterations for calculating the PLS results and 7 stop criterion values (Hair, J. F., Hult, G. T. M., Ringle, C. M., \& Sarstedt, 2013) so that the PLS algorithm could stop when the change in the outer weights between two consecutive iterations was smaller than 7 stop criterion value. We then used a nonparametric bootstrapping procedure to test the statistical significance of various PLS-SEM results that include path coefficients and $\mathrm{R}^{2}$ values. Bootstrapping is a resampling technique with replacement from the sample data to generate empirical sampling distribution. In our case, we used 5000 subsamples and a two-tailed test type with a 0.1 significance level (Hair, J. F., Hult, G. T. M., Ringle, C. M., $\&$ Sarstedt, 2013).

\section{Descriptive Statistic}

We had a 7-scale Likert scale for the responses to the items, so we categorized the scale in terms of percentage value to analyze the average score for each item and overall impression of the constructs. We collected scores for all the items in perceived ease of use, perceived usefulness, quality of system, trust, security, privacy, attitudes, and intention to use constructs of our model. The scores obtained for selected constructs indicate that user perceptions on the benefits of using BBS should be maintained by making improvements to achieve a higher level of score category. The preliminary descriptive statistic of the obtained data is shown in Fig. 4 which informs that the average results of the constructs are above $71.43 \%$, so they qualified for the quite high category (Shrestha \& Vassileva, 2019a). The comparatively lower pre-test scores indicate that participants developed confidence and trust towards the overall usefulness, usability, attitudes and intention to use the BBS after they used the SCS and DSS. Furthermore, higher scores for PEOS, PU, QOS for SCS over DSS signify that the participants feel easier to use SCS compared to the participants who participated in the DSS part of the study. However, all the selected constructs in our study provided a significant impression in the context of both BBS.

\section{Measurement Validation}


556 We checked the measurement model with the exploratory factor analysis by testing the

557

558

559

560

561

562

563

564

565

566

567

568

569

570

571

572

573

574

575

576

577

578

579

580

581

582

583

584

585

586

587

588

589

590

591

592

593

594

595

convergent validity, reliability of measures and discriminant validity.

For Exploratory Factor Analysis, we first checked the factor loadings of individual items, as shown in Table 2, to see whether the items in each variable loaded highly on its own construct over the other respective constructs. According to (Chin, Peterson, \& Brown, 2008), factor loadings exceeding 0.60 can be considered as significant. In our study, all the indicators in the measurement models had a factor loading of value greater than 0.60 except for Item 4 in the construct Behavioral Privacy-Technical Protection (BP-TP4). Since the square of factor loading is directly translated as item's reliability, the item BP-TP4, "I regularly clear my browser's history" with a very low loading value of 0.39 indicated that its communality value would be only 0.15 , and thus should be avoided in the model. Although we used the validated constructs, our exploratory analysis detected that the item BP-TP4 had a weak influence on the Behavioral Privacy construct.

For the Convergent Validity of each construct measure, we calculated the Average Variance Extracted (AVE) and Composite Reliability (CR) from the factor loading. AVE for each construct should exceed the recommended level of 0.50 so that over $50 \%$ of the variances observed in the items were accounted for by the hypothesized constructs, and CR should also be above 0.75 to publish results (Hair, Black, Babin, \& Anderson, 2014). In our study, the AVE reported in Table 3 exceeds 0.50 for all the constructs except for Beh Privacy-Technical Protection (BP-TP). However, CR for each construct was above 0.75 (acceptable), confirming that it measures the construct validity of the model. Since the BP-TP had the item BP-TP4 of very low factor loading along with an AVE value of 0.469 , it suggests that the factor BP-TP did not bring significant variance for the variables (items/questions) to converge into a single construct which means BP-TP items are a less-than-effective measure of the latent construct. We also justify this with the exceptionally low rho_A value for the construct BP-TP.

Table 3 shows the calculated rho_A value (Dillon-Goldstein's rho) for checking the internal consistency to justify the reliability of each measure. The rho_A evaluates the within-scale consistency of the responses to the items of the measures of constructs and is a better reliability measure than Cronbach's alpha in SEM (Demo, Neiva, Nunes, \& Rozzett, 2012). In our study, as recommended, rho_A for each construct was greater than 0.70 except for BP-TP which had a 0.28 rho value. Therefore, this also supports our decision of removing the behavioral privacy constructs from the post-tests for both SCS and DSS. We assumed that using the BBS simply does not influence the user's behavioral perception of privacy. So, we were interested to see if there is any significant effect on the attitudinal aspect of privacy.

For assessing the Discriminant Validity of measures, we calculated the square root of the AVE (along the diagonals) of each construct as shown in Table 4. To lean towards discriminant

PeerJ Comput. Sci. reviewing PDF | (CS-2020:10:53488:1:1:NEW 25 Mar 2021) 
596

597

598

599

600

601

602

603

604

605

606

607

608

609

610

611

612

613

614

615

616

617

618

619

620

621

622

623

624

625

626

627

628

629

630

631

632

633

634

validity, (Fornell \& Larcker, 1981) recommended having low correlations between the measure of interest and the measures of other constructs. In our model, we observed those diagonal values for each construct exceeded other corresponding values, which are the intercorrelations of the given construct with the other remaining constructs. This pointed out that the measures of each construct which was theoretically supposed to be not overlapping with measures of other variables are in fact, unrelated in our model.

\section{Partial Least Square Path Modeling}

To begin our Structural Equation Modeling (SEM) analysis, we built the models for the general population in the context of the pre-test (prototype model) and two subsystems SCS and DSC. We characterized the models by looking into coefficients of determination ( $\mathrm{R}^{2}$ 's), path coefficients ( $\beta$ 's) and corresponding $\mathrm{P}$-value. $\mathrm{R}^{2}$ determines the variance of a given construct explained by antecedents, $\beta$ captures the strength of the relationship between the selected constructs and P-value determines the statistical significance of the models (Shrestha \& Vassileva, 2019a). According to Chin's guideline (Chin, Marcelin, \& Newsted, 2003), a path coefficient should be equal to or greater than 0.2 to be considered relevant. A model is statistically somewhat significant $\left({ }^{*} p\right)$ when $p$-value $<0.1$, statistically quite significant $(* * p)$ when $\mathrm{p}$-value $<0.01$ and statistically highly significant $(* * * \mathrm{p})$ when $\mathrm{p}$-value $<0.001$. Table 5 , Table 6 and Table 7 each show the standardized path coefficient $(\beta)$, t-statistics, $p$-value and $\mathrm{R}^{2}$ across selected constructs for pre-test, SCS and DSS, respectively. The indirect and total effects of one construct over another construct in the presence of mediating constructs were also computed alongside.

\section{Validation of Hypotheses}

For pre-test in the context of prototype model, the model presented in Fig. 5 shows causal relationship between perceived attitudinal privacy, behavioral privacy-technical protection, behavioral privacy-general caution, perceived security, trust and attitude towards BBS constructs. Considering the direct effects, attitudinal privacy (privacy concern) had very high significant effects on security $(\beta=0.64 ; \mathrm{P}<0.001)$ and trust $(\beta=0.313 ; \mathrm{P}<0.001)$, but an insignificant effect on attitudes towards system $(\beta=0.176 ; \mathrm{P}>0.05)$. In addition, attitudinal privacy also positively affected behavioral privacy-general caution $(\beta=0.465 ; \mathrm{P}<0.001)$ but had an insignificant effect on behavioral privacy-technical protection $(\beta=0.068 ; \mathrm{P}>0.1)$. The effect of security on trust was also highly significant $(\beta=0.529 ; \mathrm{P}<0.001)$, but insignificant on attitudes towards BBS $(\beta=-0.104 ; \mathrm{P}>0.1)$. Finally, trust had a high significant positive effect on attitudes towards BBS $(\beta=0.724 ; \mathrm{P}<0.001)$. Thus, hypotheses H7, H8, H10, H11 and H13 were supported, but H9, H12, and H14 were rejected in the context of pre-test. Moreover, trust, privacy and security explain $59.8 \%$ of variance in attitudes towards BBS $\left(\mathrm{R}^{2}=0.598\right)$, security and privacy explain $58.8 \%$ of variance in trust $\left(\mathrm{R}^{2}=0.588\right)$, privacy explains $40.6 \%$ of variance in security $\left(\mathrm{R}^{2}=0.406\right)$, whereas attitudinal privacy explains very low, $21.6 \%$ of variance on 
635 behavioral privacy-general caution $\left(\mathrm{R}^{2}=0.216\right)$ and $0.5 \%$ on behavioral privacy-technical

636 protection. $\mathrm{R}^{2}$ value higher than 0.26 indicates a substantial model (Muller \& Cohen, 1989).

637

638

639

640

641

642

643

644

645

646

647

648

649

650

651

652

653

654

655

656

657

658

659

660

661

662

663

664

665

666

667

668

669

670

671

672

673

674

For post-test study in the context of SCS, the model presented in Fig.6 shows causal relationship between perceived ease of use, perceived usefulness, quality of system, security, privacy, trust, attitude towards SCS and intention to use SCS constructs. Considering the direct effect, perceived ease of use had quite significant effect on perceived usefulness $(\beta=0.356 ; \mathrm{P}<0.01)$ but insignificant effect on intention to use $(\beta=0.058 ; \mathrm{P}>0.1)$; therefore, $\mathrm{H} 1$ was supported and $\mathrm{H} 2$ was rejected. Perceived usefulness had relevant but somewhat significant effect on intention to use $(\beta=0.284 ; \mathrm{P}<0.1)$; thus, $\mathrm{H} 3$ was also supported. Quality of system had positive significant effect on perceived usefulness $(\beta=0.509 ; \mathrm{P}<0.001)$ and somewhat significant effect on intention to use SCS $(\beta=0.338 ; \mathrm{P}<0.1)$; therefore, $\mathrm{H} 4$ and $\mathrm{H} 5$ were supported. Attitude towards SCS had relevant but somewhat significant effect on intention to use $(\beta=0.25 ; \mathrm{P}<0.1)$; therefore, $\mathrm{H} 6$ was supported. The effect of trust was highly significant on attitude towards SCS ( $\beta=0.534 ; \mathrm{P}<0.001$ ); therefore, $\mathrm{H} 7$ was supported. Perceived privacy had positive significant effects on trust $(\beta=0.609 ; \mathrm{P}<0.001)$, attitudes towards SCS $(\beta=0.325 ; \mathrm{P}<0.01)$ and perceived security $(\beta=0.654 ; \mathrm{P}<0.001)$; therefore, $\mathrm{H} 8, \mathrm{H} 9$ and $\mathrm{H} 10$ were supported. Perceived security had insignificant effect on trust $(\beta=0.212 ; \mathrm{P}>0.1)$ and attitudes towards SCS $(\beta=-0.165 ; \mathrm{P}>$ $0.1)$; therefore, $\mathrm{H} 13$ and $\mathrm{H} 14$ were rejected. In the following, the explained variances include perceived usefulness $\left(\mathrm{R}^{2}=0.571\right)$, security $\left(\mathrm{R}^{2}=0.428\right)$, trust $\left(\mathrm{R}^{2}=0.585\right)$, attitude towards SCS $\left(\mathrm{R}^{2}=0.5\right)$ and intention to use $\left(\mathrm{R}^{2}=0.612\right)$. Therefore, $\mathrm{R}^{2}$ value higher than 0.26 indicated a substantial model for SCS (Muller \& Cohen, 1989).

Similarly, for post-test study in the context of DSS, the model presented in Fig.7 shows causal relationship between perceived ease of use, perceived usefulness, quality of system, security, privacy, trust, attitude towards DSS and intention to use DSS constructs. Considering the direct effect, perceived ease of use had significant effect on perceived usefulness $(\beta=0.488 ; \mathrm{P}<0.001)$ but insignificant effect on intention to use $(\beta=-0.173 ; \mathrm{P}>0.1)$; therefore, H1 was supported and $\mathrm{H} 2$ was rejected. Perceived usefulness had relevant but somewhat significant effect on intention to use $(\beta=0.495 ; \mathrm{P}<0.1)$; thus, $\mathrm{H} 3$ was also supported. Quality of system had positive significant effect on perceived usefulness $(\beta=0.427 ; \mathrm{P}<0.01)$, but insignificant effect on intention to use DSS ( $\beta=-0.009 ; \mathrm{P}>0.1)$; therefore, $\mathrm{H} 4$ was supported and $\mathrm{H} 5$ was rejected. Attitude towards DSS had relevant and positive significant effect on intention to use $(\beta=0.554$; $\mathrm{P}<0.001$ ); therefore, $\mathrm{H} 6$ was supported. The effect of trust was highly significant on attitude towards DSS $(\beta=0.637 ; \mathrm{P}<0.001)$; therefore, $\mathrm{H} 7$ was supported. Perceived privacy had positive significant effects on trust $(\beta=0.495 ; \mathrm{P}<0.001)$ and perceived security $(\beta=0.82 ; \mathrm{P}<$ $0.001)$, but insignificant effect on attitudes towards DSS ( $\beta=0.097 ; \mathrm{P}>0.1)$; therefore, H8 and H10 were supported but $\mathrm{H} 9$ was rejected. Perceived security had significant effect on trust $(\beta=$ $0.369 ; \mathrm{P}<0.01)$ but insignificant effect on attitudes towards DSS $(\beta=-0.012 ; \mathrm{P}>0.1)$;

74 therefore, H13 was supported but $\mathrm{H} 14$ was rejected. In the following, the explained variances 
675 include perceived usefulness $\left(\mathrm{R}^{2}=0.708\right)$, security $\left(\mathrm{R}^{2}=0.679\right)$, trust $\left(\mathrm{R}^{2}=0.683\right)$, attitude

676 towards $\operatorname{SCS}\left(\mathrm{R}^{2}=0.5\right)$ and intention to use $\left(\mathrm{R}^{2}=0.678\right)$. Therefore, $\mathrm{R}^{2}$ value higher than 0.26

677 indicated a substantial model for DSS (Muller \& Cohen, 1989). Table 8 summarizes the

678 validation of our study's hypotheses.

679

680

\section{Total Effect Analysis}

681 To address the first research question, we present the total effect of antecedents from the trust

682 model on attitudes towards BBS as shown in Fig. 8. In the pre-test model, trust had the strongest 683 total effect on attitudes towards BBS $(\beta=0.732 ; \mathrm{P}<0.001)$, followed by privacy on attitudes 684 towards $\operatorname{BBS}(\beta=0.586 ; \mathrm{P}>0.001)$ and security on attitudes towards $\mathrm{BBS}(\beta=0.283 ; \mathrm{P}<0.1)$, 685 which was marginally significant. In the SCS model, privacy had the strongest influence on 686 attitudes towards SCS $(\beta=0.62 ; \mathrm{P}<0.001)$, followed by trust on attitudes towards SCS $(\beta=$ $6870.538 ; \mathrm{P}<0.001)$, while security had no significant total effect on attitudes towards SCS $(\beta=-$ $6880.049 ; \mathrm{P}>0.1)$. Finally, the total effect statistic for the DSS model was similar to that of the pre689 test model, with respect to first two strongest design constructs which were trust $(\beta=0.637 ; \mathrm{P}<$ $6900.001)$, followed by privacy $(\beta=0.596 ; \mathrm{P}>0.001)$. Security turned out to have no significant 691 effect on attitude towards $\operatorname{DSS}(\beta=0.223 ; \mathrm{P}>0.1)$.

692

693 To address the second research question, we present the total effect of the perceived design 694 constructs on intention to use from SCS and DSS model as shown in Fig. 9. In SCS model, 695 quality of system had the strongest total effect on intention to use SCS $(\beta=0.49 ; \mathrm{P}<0.001)$. 696 Perceived usefulness had a weak total effect on intention to use SCS $(\beta=0.297 ; \mathrm{P}<0.1)$, while 697 privacy had no significant total effect on intention to use SCS $(\beta=0.156 ; \mathrm{P}>0.1)$, followed by 698 perceived ease of use on intention to use $\operatorname{SCS}(\beta=0.153 ; \mathrm{P}>0.1)$ and security on intention to 699 use SCS $(\beta=-0.01 ; \mathrm{P}>0.1)$. In the context of DSS, Perceived usefulness had the strongest total 700 effect on intention to use DSS $(\beta=0.495$; P $<0.01)$, followed by trust on intention to use DSS ( $\beta$ $701=0.353 ; \mathrm{P}<0.001)$ and privacy on intention to use DSS $(\beta=0.33 ; \mathrm{P}<0.001)$. Quality of system 702 had no significant total effect on intention to use DSS $(\beta=0.202 ; \mathrm{P}>0.1)$, followed by security 703 on intention to use DSS $(\beta=0.124 ; \mathrm{P}>0.1)$ and perceived ease of use on intention to use DSS $(\beta$ $704=0.069 ; \mathrm{P}>0.1)$.

705

706

707

708

\section{Mediation Analysis}

To address our third, fourth and fifth research questions, we carried out the indirect effect

709 analysis. We first investigated the mediating effect of security and/or trust over the relationship between privacy and attitudes towards BBS, then investigated the mediating effect of trust over

710 the relationship between security and attitudes towards BBS, and finally investigated a similar

711

712 mediating effect of perceived usefulness over the relationship between ease of use/quality of

713 no need to check for the indirect effect if the direct effect is insignificant in the model. 714 
715 So, for the pre-test model as presented in Table 5, we found the observed indirect effects for the

716 selected predictors in the presence of mediating variables in the pre-test model. In the presence

717 of mediating effect of both trust and security, the effect of privacy on attitude towards BBS

718 slightly decreased from $(\beta=0.584 ; \mathrm{T}=6.868 ; \mathrm{P}<0.001$ while excluding both trust and security)

719 to $(\beta=0.412 ; \mathrm{T}=4.466 ; \mathrm{P}<0.001)$ with the variance accounted for (VAF) value of 0.703 . The

720 VAF is calculated as the ratio of the indirect path coefficient to the total path coefficient. With

$72170.3 \% \mathrm{VAF}$, trust and security had a partial mediation effect between privacy and attitude

722 towards BBS. While analyzing the individual mediating effects between privacy and attitudes

723 towards BBS, trust alone had positive significant effect $(\beta=0.226 ; \mathrm{T}=3.151 ; \mathrm{P}<0.01)$, but

724 security alone had no significant effect $(\beta=-0.068 ; \mathrm{T}=0.852 ; \mathrm{P}>0.1)$. So, our finding

725 suggested that only trust played a crucial mediating role while security had no significant effect

726 between privacy and attitudes toward BBS. Similarly, in the presence of mediating effect of

727 trust, the effect of security on attitude towards BBS slightly decreased from $(\beta=0.538 ; \mathrm{T}=6.14$;

$728 \mathrm{P}<0.001$ while excluding Trust $)$ to $(\beta=0.391 ; \mathrm{T}=4.348 ; \mathrm{P}<0.001)$ with the variance

729 accounted for (VAF) value of 1.382 . With $138 \% \mathrm{VAF}$, trust had a perfect mediation effect

730 between security and attitude towards BBS.

731

732 For SCS model, as presented in Table 6, in the presence of mediating effect of trust and security,

733 the effect of privacy on attitude towards SCS slightly decreased from $(\beta=0.619 ; \mathrm{T}=8.504 ; \mathrm{P}<$

7340.001 while excluding both trust and security) to $(\beta=0.293 ; \mathrm{T}=2.23 ; \mathrm{P}<0.1)$ with the variance

735 accounted for (VAF) value of 0.473 . With $47.3 \% \mathrm{VAF}$, trust and security had a partial mediation

736 effect between privacy and attitude towards SCS. While analyzing the individual mediating

737 effects between privacy and attitudes towards SCS, trust alone had positive significant effect $(\beta=$

738 0.326; $\mathrm{T}=2.683 ; \mathrm{P}<0.01)$, but security alone had no significant effect $(\beta=-0.108 ; \mathrm{T}=1.466 ; \mathrm{P}$

$739>0.1$ ). So, our finding suggested that only trust played a crucial mediating role while security

740 had no significant effect between privacy and attitudes toward SCS. In the same SCS model,

741 with the presence of mediating effect of trust, the effect of security on attitude towards SCS

742 became insignificant from $(\beta=0.384 ; \mathrm{T}=3.304 ; \mathrm{P}<0.001$ while excluding trust $)$ to $(\beta=0.122$;

$743 \mathrm{~T}=1.191 ; \mathrm{P}>0.1$ ) with the variance accounted for (VAF) value of -2.489 . Therefore, trust had

744 no mediating effect between security and attitude towards SCS since after adding trust predictor

745 as a mediator, the indirect effect on attitude towards SCS became non-significant while the direct

746 effect was also insignificant. Furthermore, in the same SCS model, with the presence of

747 mediating effect of perceived usefulness, the effect of quality of system on intention to use SCS

748 became insignificant from $(\beta=0.705 ; \mathrm{T}=11.127 ; \mathrm{P}<0.001$ while excluding usefulness $)$ to $(\beta=$

$7490.152 ; \mathrm{T}=1.557 ; \mathrm{P}>0.1)$ with the variance accounted for (VAF) value of 0.31 . Therefore,

750 perceived usefulness had no significant mediating effect between quality of system and intention

751 to use SCS since after adding perceived usefulness predictor as a mediator, the indirect effect on

752 intention to use SCS became non-significant while the direct effect was still significant.

753 In addition, with the presence of mediating effect of perceived usefulness, the ease of use on

754 intention to use SCS became insignificant from $(\beta=0.559 ; \mathrm{T}=7.035 ; \mathrm{P}<0.1$ while excluding 
755

756

757

758

759

760

761

762

763

764

765

766

767

768

769

770

771

772

773

774

775

776

777

778

779

780

781

782

783

784

785

786

787

788

789

790

791

792

793

794

usefulness) to ( $\beta=0.108 ; \mathrm{T}=1.363 ; \mathrm{P}>0.1)$ with the variance accounted for $(\mathrm{VAF})$ value of 0.706 . Therefore, perceived usefulness had no significant mediating effect between ease of use and intention to use SCS since after adding perceived usefulness predictor as a mediator, the indirect effect on intention to use SCS became non-significant while the direct effect was also non-significant.

Finally, in the DSS model, as presented in Table 7, in the presence of mediating effect of trust and security, the effect of privacy on attitude towards DSS slightly decreased from $(\beta=0.6 ; \mathrm{T}=$ 6.134; $\mathrm{P}<0.001$ while excluding both trust and security) to $(\beta=0.5 ; \mathrm{T}=2.319 ; \mathrm{P}<0.1)$ with the variance accounted for (VAF) value of 0.839 . With $83.9 \% \mathrm{VAF}$, trust and security had a partial mediation effect between privacy and attitude towards DSS. While analyzing the individual mediating effects between privacy and attitudes towards DSS, trust alone had positive significant effect $(\beta=0.316 ; \mathrm{T}=2.726 ; \mathrm{P}<0.01)$, but security alone had no significant effect $(\beta=-0.01 ; \mathrm{T}$ $=0.053 ; \mathrm{P}>0.1)$. So, our finding suggested that only trust played a crucial mediating role while security had no significant effect between privacy and attitudes toward DSS. In the same DSS model, no mediation effect was observed for trust between security and attitudes towards DSS. Furthermore, in the same DSS model, with the presence of mediating effect of perceived usefulness, the effect of quality of system on intention to use DSS reduced from $(\beta=0.66 ; \mathrm{T}=$ 7.82; $\mathrm{P}<0.001$ while excluding usefulness) to $(\beta=0.212 ; \mathrm{T}=1.846 ; \mathrm{P}<0.1)$ with the variance accounted for (VAF) value of 1.05 . Therefore, perceived usefulness had a complete significant mediating effect between quality of system and intention to use DSD since after adding perceived usefulness predictor as a mediator, the indirect effect on intention to use DSD became significant while the direct effect was insignificant. This suggested that the indirect significant path between quality of system and intention to use DSD was contributed by perceived usefulness predictor construct. In addition, with the presence of mediating effect of perceived usefulness, the effect of ease of use on intention to use reduced from $(\beta=0.588 ; \mathrm{T}=6.385 ; \mathrm{P}<$ 0.001 while excluding usefulness) to $(\beta=0.242 ; \mathrm{T}=1.946 ; \mathrm{P}<0.1)$ with the variance accounted for (VAF) value of 3.507. Therefore, perceived usefulness had a complete mediating effect between ease of use and intention to use DSD since after adding perceived usefulness predictor as a mediator, the indirect effect on intention to use DSD became significant while the direct effect was non-significant. This suggested that the indirect significant path between perceived ease of use and intention to use DSD was contributed by perceived usefulness predictor construct.

\section{Discussion}

The purpose of this study is to evaluate the user acceptance of a working blockchain-based system by observing the attributes affecting the development of users' attitudes and intention to use the system. We achieved the goal of our research by testing the augmented TAM with a Trust model on our application (BBS) that is built using blockchain technology. The empirical study validates our research model and supports most of the research hypotheses that were set

Peer) Comput. Sci. reviewing PDF | (CS-2020:10:53488:1:1:NEW 25 Mar 2021) 
795

796

797

798

799

800

801

802

803

804

805

806

807

808

809

810

811

812

813

814

815

816

817

818

819

820

821

822

823

824

825

826

827

828

829

830

831

832

833

considering the aim of this study. We also identified different issues influencing users' attitudes and intentions to adopt BBS by considering observed facts from the causal relationships and their implications. According to (Gefen et al., 2003), extending TAM with trust model is well justified for its effectiveness in improving the predictive power of the explored issues associated with the acceptance of online services. BBS can be considered as a set of online services, so applying the TAM augmented with trust, as we did in our study, is justified.

The major contribution of our study to the existing literature of blockchain and distributed ledger technologies is to uncover the dimensions and role of trust alongside primary TAM-based design predictors and their causal relationship with users' attitudes and behavioral intention to accept such technologies.

According to the results from our research, TAM-based predictors or trust constructs cannot be applied uniformly to BBS. Depending on the specifics of the BBS, the relationships between perceived trust, perceived security, perceived privacy and attitudes towards the system might change. In this study, there was a customer-specific system: SCS and a company-specific system: DSS. Every participant who completed the post-survey for DSS also completed the postsurvey for SCS with 66 participants completing the post-survey for SCS and 53 participants completing the post-survey for DSS. There was no major difference between the users of each system that could lead to the difference between the responses of the two surveys. With the SCS, the user engaged with the point of view of a customer, whereas the DSS had the user engaged the system as an enterprise's system administrator.

A previous study by (Buchanan et al., 2007) suggests that attitudinal privacy, in the privacy model, correlates significantly with behavioral privacy-general caution but not significantly with the technical protection factor. The findings of our current research also indicate comparable results. Users who are concerned with their data privacy tend to be more cautious and careful about protecting it, however, if the users are technically competent, they have already used tools to protect their privacy such as clearing the browser's cache and history, using spyware etc., so they become less concerned about their privacy infringement.

Based on our research findings, perceived ease of use does not impact behavioral intention to use the actual BBS unlike in our previous study on the blockchain-based prototype model, where ease of use was significant in the initial stage (Shrestha \& Vassileva, 2019a). This is because users perceive BBS, a user-friendly web application, easier to learn and operate. Based on representative literature such as (Liu, Chen, Sun, Wible, \& Kuo, 2010), UI design is the most significant item that affects perceived ease of use. Users, instead of being more concerned about learning to use the system, are concerned about the usefulness and overall performance of the BBS. Previous studies by ((Venkatesh, Morris, Davis, \& Davis, 2003); (Chan \& Lu, 2004); 
834 (Pikkarainen, Pikkarainen, Karjaluoto, \& Pahnila, 2004); (Roca et al., 2009)) confirm that

835 usability (ease of use) remains non-significant to develop an intention to use the system.

836

837 According to the results of our study, we deduce perceived ease of use and quality of BBS as

838 significant predictors of the usefulness construct. When users find BBS easier to use and believe

839 they can be skillful in using it, they will consider the system as more useful to improve their

840 performance and productivity. This is also confirmed by previous studies (Gefen et al., 2003; Liu

841 et al., 2010). In our system, SCS allows customers to set their data sharing preferences and

842 receive incentives for sharing their data as per the smart contracts, while DSS guarantees

843 companies that the customer data they access have integrity and confirm provenance. So, users of

844 each system, who feel more satisfied with these features, develop a higher understanding of its

845 perceived usefulness. Eventually, with positive feelings about the usefulness of the BBS, users

846 develop a stronger behavioral intention to accept the system. Since the quality of system has an

847 insignificant direct effect on the intention to use the system for DSS, its effect through perceived

848 usefulness is found out to be a significant positive effect in our study which is per the suggestions

849 made by (DeLone \& McLean, 1992).

850

851

Moreover, the empirical results of our study also confirm a significant positive effect of the users'

852 attitudes on their intention to use the BBS and suggest that the most important antecedent of

853

854 attitudes towards using BBS is trust which is also supported by the previous studies

855

856

857

858

859

860 (Bhattacherjee, 2002), which confirms that the trust predictor significantly influences the user's decision to adopt the online services. Therefore, familiarity with the significance of the underlying blockchain technology and the honesty of the companies to keep its promises of protecting privacy, securing information and incentivizing customers for sharing their data bring a higher level of trust and stimulate positive attitudes of customers towards using the SCS. Similarly, trusting the blockchain technology for its integrity and dependability significantly improves the company's attitudes towards adopting the DSS.

861

862

According to (Shin, 2010), trust has a moderating effect on perceived security and perceived

863 privacy when it comes to adopting social networking sites. Perceived security has a mediating 864 effect on perceived privacy that correlates to trust (Rios et al., 2017). The findings from our study

865 suggest that perceived security has a direct effect on trust in the context of the prototype model and DSS. Outside of this, there is no significant relationship between security and other constructs. Perceived privacy has a direct effect on user trust and perceived security, which reinforces the findings by (Rios et al., 2017) that claims perceived security and perceived privacy are related. Based on our findings, the direct effect of perceived privacy on users' attitudes 871 models.

872

873 Our findings suggest that the influence of perceived privacy and perceived security depends 874 strongly on which blockchain-based system users interact with. When answering the initial pre- 
875 test survey, participants have no system to base their ideas on. So, security, privacy, trust and BBS

876 become abstract concepts. As abstract concepts, participants believe privacy affects security,

877 security and privacy affect trust, and trust affects their intention to use the system. However, they

878 are not aware of any direct effect of privacy and security on their choice to use the system.

879

880 In our study, we see that after using the SCS, there is a significant effect of perceived privacy on

881 the user's attitude towards BBS. Yet, the pre-test and DSS survey results show that participants

882 feel perceived privacy does not positively affect their attitudes towards BBS. Perceived privacy's

883 effect on user's attitudes towards BBS is only significant with a customer-specific BBS like SCS

884 but not significant with a company-specific BBS like DSS. However, trust has either a partial or

885 complete mediating role in all kinds of BBS which is consistent with prior research (Shin, 2010).

886

887

Based on the initial pre-test survey results, we deduce that participants feel security protection

888

889

890

891

892

893

894

895

896

897

898

899

900

901

902

903

904

905

906

907

908

909

910

911

912

913

914

915

mechanisms are an important indicator to trust the system. However, after using the SCS, we learn that perceived security tends to be an insignificant predictor of trust. For the DSS, the effect of perceived security on trust is once again significant. It may be because after experiencing the real-life blockchain-based system, respondents using the SCS becomes aware of the underlying security infrastructure of blockchain and smart contracts, but once they learn that the business process models deployed via smart contracts are committed on a public blockchain, they may care more about privacy and think less about underlying security. As they are not concerned about security, they want to have control over their data instead, the relative significance of perceived privacy to trust SCS for these users is higher. On the other hand, respondents experiencing DSS to access customer data may not care much about privacy since they are already putting their information through transparent processes for customers and other enterprises. Instead, they may care more about secure transactions, mitigating anomalies and malicious behavior in their consortium network and cyber-resilient smart contracts. Therefore, perceived security may significantly affect trust in an abstract context, but with a specific context, it may be significant for a model like SCS and may not be significant for a model like DSS.

Prior research on the effect of perceived security and perceived privacy on user trust are mixed. (Shin, 2019) found a significant moderating effect of security on trust, but participants had no real interaction with a system. Studies on non-blockchain online services had comparable results. (McCole, Ramsey, \& Williams, 2010) found that perceived privacy and perceived security moderates the effect of trust. (Eastlick, Lotz, \& Warrington, 2006) empirically showed that the relationship between privacy concerns and trust was the third strongest of all relationships studied. (Chellappa \& Pavlou, 2002) argued that perceived security is a stronger predictor of trust. All four of these studies were abstract and did not have participants engage with a real system before answering their survey. These results support our initial pre-test results. Without interacting with any system, participants often consider privacy, security, and trust to be strongly related.

Peer] Comput. Sci. reviewing PDF | (CS-2020:10:53488:1:1:NEW 25 Mar 2021) 
916 In previous studies, where participants engaged with online services such as online shopping, 917 perceived security had a stronger effect. Both (Belanger, Hiller, \& Smith, 2002) and (Kim, 918 Steinfield, \& Lai, 2008) found that perceived security had a stronger effect than perceived 919 privacy on consumer behavior. (Roca et al., 2009) found that perceived privacy did not influence 920 trust, but they did not consider the influence of security factors moderating privacy concerns in 921 their model based on extended TAM. These do not align with our findings from when 922 participants used the SCS. Our study found security has no significant relationship to trust in 923 SCS, while privacy significantly affects trust and attitudes towards BBS.

924

925

The discrepancy between results from abstract studies and studies with concrete systems shows

926

927 how important it is to focus on the latter. Although the abstract studies show there was a strong

928

929 relationship between trust, privacy, and security, the studies with actual eCommerce systems have mixed and inconclusive results. Furthermore, studies on eCommerce systems focus on the

930 customer. Few relevant studies focus on the company's trust and its intention to use the technology. Therefore, we cannot find other results to compare to the current study's finding that for DSS perceived security positively affects trust in BBS, and trust completely mediates the influence of privacy on attitudes towards adopting the BBS. Also, based on our pre-test and posttest results, there is no mediating effect of security over the perceived privacy on the users' attitudes towards BBS. Further study is needed with specific types of BBS to see if there are more BBS types other than customer-specific and company-specific and to better understand 937 which trust construct is significant for each type of system.

939

Our study also brings a methodological contribution to the literature with the use of partial least square structural equation modelling (PLS-SEM) to analyze the user acceptance of the concrete

940 blockchain-based application. PLS is component-based and can model the latent constructs under

941

942 conditions for smaller sample sizes by maximizing the explained variance of dependent indicators and use multiple regressions to observe the effect of predictors on the response variables (Chin et al., 2008; Hair, J. F., Hult, G. T. M., Ringle, C. M., \& Sarstedt, 2013). Furthermore, this study contributes to the methodology by adopting Dillon-Goldstein's rho, for estimating internal consistency reliability, which is suggested as an always better choice than conservative Cronbach's alpha in the presence of skew items and smaller samples (Demo et al., 2012).

949

950

951

952

953

954

955

\section{Limitations}

The main limitation of our study is that our findings are based on smaller targeted population size and only on two specific types of BBS. Therefore, the results may not generalize to the broader population and to any type of BBS. Further study may consider using a larger sample with specific types of BBS; to explore BBS types other than customer-specific and companyspecific, and to better understand which trust antecedent is significant for each type of system. Moreover, an obvious limitation comes from using the same participants for both systems. With most respondents who participated in the DSS study also completed the SCS study, they also 
956 satisfy the inclusion criteria of DSS while doing the SCS study. The DSS study had participants

957 only with a technology background. Also by taking on separate roles, participants may have

958 experienced different motivations that skewed their survey results, so further study is needed to

959 draw any conclusions about the role users take and what factors influence their desire to use the

960 specific BBS. Likewise, the results showed that almost 79\% of participants for SCS had a basic

961 knowledge of blockchain technology while 19\% had advanced knowledge and some of the

962 participants belonged to academia. To address this, we need to consider an underlying effect of

963 participants' background on their behavioral intention to use BBS. Therefore, this study offers an

964 opportunity for future exploration of BBS to consider multigroup analysis based on participants'

965 demography and background knowledge when analyzing the endogenous and exogenous

966 variables, which will further explain the user acceptance of the BBS.

967

\section{Conclusions}

969 In this paper, we presented the augmented TAM with trust model on our real-life blockchain-

970 based system (BBS), which comprises two subsystems: Shopping Cart System (SCS) and Data

971 Sharing System (DSS). The main contribution of our study to the body of knowledge is that, to

972 the best of our knowledge, this study is the first to examine the augmented TAM with trust

973 model using real-life concrete blockchain-based applications. The empirical study validated our

974 research model and supported most of the research hypotheses that we set based on our research.

975 Our findings suggested that TAM-based predictors and trust constructs cannot be applied

976 uniformly to BBS. Depending on the specifics of the BBS, the relationships between perceived

977 trust, perceived security, perceived privacy and attitudes towards the system might change. In

978 SCS trust was the strongest determinant of attitudes towards the system, but in DSS, privacy was

979 the strongest determinant of attitudes towards the system. Quality of system had the strongest

980 total effect on intention to use SCS, while perceived usefulness had the strongest total effect on

981 intention to use DSS. Trust significantly influenced the users' attitudes towards both types of

982 BBS, while security did not have any effect on users' attitudes toward BBS. In SCS, privacy

983 positively affected trust, but security had no significant effect on trust, whereas, in DSS, both

984 privacy and security significantly influenced trust. In both BBS, trust had a moderating effect on

985 privacy that correlated directly with attitudes towards BBS, whereas security had no mediating

986 effect between privacy and attitudes towards BBS. Hence, we recommend that while

987 implementing and upgrading blockchain-based solutions, the decision-makers should carefully

988 consider the trust patterns and address the associated privacy challenges of the users. Designers

989 and decision-makers for the industries should know that the effect of trust antecedents is context-

990 dependent whether it is customer or company-oriented. For the development of customer-

991 oriented BBS, the effect of a privacy-aware system to influence users' attitudes toward BBS is

992 relevant. For the development of a company-oriented BBS, additional security measures must

993 also be carefully addressed to significantly influence users' trust in BBS, which in turn positively

994 leads to a higher intention to adopt the system. In future work, we plan to investigate multigroup

995 analysis based on participants' background knowledge when analyzing the latent variables and 
996 perform the qualitative analysis based upon the respondents' feedback, which will further

997

998

999

1000

1001

1002

1003

1004

1005

1006

1007

1008

1009

1010

1011

1012

1013

1014

1015

1016

1017

1018

1019

1020

1021

1022

1023

1024

1025

1026

1027

1028

1029

1030

1031

1032

1033

1034

1035

1036

1037

1038

1039

1040

explain the user acceptance of the BBS.

\section{Acknowledgements}

We thank Mr. Kiemute Oyibo of the University of Waterloo for his helpful discussion and consultation about the correctness of the statistical analysis.

\section{References}

Amin, H., \& Ramayah, T. (2010). SMS Banking: Explaining the Effects of Attitude, Social Norms and Perceived Security and Privacy. The Electronic Journal of Information Systems in Developing Countries, 41(1), 1-15. https://doi.org/10.1002/j.1681-4835.2010.tb00291.x

Baron, R. M., \& Kenny, D. A. (1986). The moderator-mediator variable distinction in social psychological research: Conceptual, strategic, and statistical considerations. Journal of Personality and Social Psychology, 51(6), 1173-1182. https://doi.org/10.1037/00223514.51.6.1173

Belanger, F., Hiller, J. S., \& Smith, W. J. (2002). Trustworthiness in electronic commerce: the role of privacy, security, and site attributes. The Journal of Strategic Information Systems, 11(3-4), 245-270. https://doi.org/10.1016/S0963-8687(02)00018-5

Bhattacherjee, A. (2000). Acceptance of e-commerce services: the case of electronic brokerages. IEEE Transactions on Systems, Man, and Cybernetics - Part A: Systems and Humans, 30(4), 411-420. https://doi.org/10.1109/3468.852435

Bhattacherjee, Anol. (2002). Individual Trust in Online Firms: Scale Development and Initial Test. Journal of Management Information Systems, 19(1), 211-241. https://doi.org/10.1080/07421222.2002.11045715

Buchanan, T., Paine, C., Joinson, A. N., \& Reips, U. D. (2007). Development of measures of online privacy concern and protection for use on the Internet. Journal of the American Society for Information Science and Technology, 58(2), 157-165. https://doi.org/10.1002/asi.20459

Bullock, A., \& Bannigan, K. (2016). Effectiveness of activity-based group work in community mental health: a systematic review. The American Journal of Occupational Therapy: Official Publication of the American Occupational Therapy Association, 65(3), 257-266. https://doi.org/10.5014/ajot.2011.001305

Burgoon, J. K., Parrott, R., Le Poire, B. A., Kelley, D. L., Walther, J. B., \& Perry, D. (1989). Maintaining and restoring privacy through communication in different types of relationships. Journal of Social and Personal Relationships. https://doi.org/10.1177/026540758900600201

Chan, S. C., \& Lu, M. Te. (2004). Understanding Internet Banking adoption and use behavior: A Hong Kong perspective. Journal of Global Information Management. https://doi.org/10.4018/jgim.2004070102

Chellappa, R. K., \& Pavlou, P. A. (2002). Perceived information security, financial liability and consumer trust in electronic commerce transactions. Logistics Information Management, 15(5/6), 358-368. https://doi.org/10.1108/09576050210447046

Chin, W. W., Marcelin, B. L., \& Newsted, P. R. (2003). A partial least squares latent variable modeling approach for measuring interaction effects: Results from a Monte Carlo simulation study and an electronic-mail emotion/adoption study. Information Systems

Peer) Comput. Sci. reviewing PDF | (CS-2020:10:53488:1:1:NEW 25 Mar 2021) 
1041

1042

1043

1044

1045

1046

1047

1048

1049

1050

1051

1052

1053

1054

1055

1056

1057

1058

1059

1060

1061

1062

1063

1064

1065

1066

1067

1068

1069

1070

1071

1072

1073

1074

1075

1076

1077

1078

1079

1080

1081

1082

1083

1084

1085

1086
Research, 14(2). https://doi.org/10.1287/isre.14.2.189.16018

Chin, W. W., Peterson, R. A., \& Brown, S. P. (2008). Structural Equation Modeling in Marketing: Some Practical Reminders. Journal of Marketing Theory and Practice, 16(4), 287-298. https://doi.org/10.2753/MTP1069-6679160402

Coppola, N. W., Hiltz, S. R., \& Rotter, N. G. (2004). Building Trust in Virtual Teams. IEEE Transactions on Professional Communication, 47(2), 95-104.

https://doi.org/10.1109/TPC.2004.828203

Cunningham, S. M. (1967). The major dimensions of perceived risk. Risk Taking and Information Handling in Consumer Behavior, 82-111.

Davis, F. D. (1989). Perceived Usefulness, Perceived Ease of Use, and User Acceptance of Information Technology. MIS Quarterly, (13), 983-1003. Retrieved from https://www.jstor.org/stable/pdf/249008.pdf

Davis, F. D., Bagozzi, R. P., \& Warshaw, P. R. (1992). Extrinsic and Intrinsic Motivation to Use Computers in the Workplace1. Journal of Applied Social Psychology, 22(14), 1111-1132. https://doi.org/10.1111/j.1559-1816.1992.tb00945.x

DeCew, J. W. (1997). Information Technology. In In Pursuit of Privacy (pp. 145-164). Cornell University Press. Retrieved from http://www.jstor.org/stable/10.7591/j.ctv75d3zc.13

DeLone, W. H., \& McLean, E. R. (1992). Information systems success: The quest for the dependent variable. Information Systems Research. https://doi.org/10.1287/isre.3.1.60

Demo, G., Neiva, E. R., Nunes, I., \& Rozzett, K. (2012). Human resources management policies and practices scale (HRMPPS): exploratory and confirmatory factor analysis. $B A R$ Brazilian Administration Review, 9(4), 395-420. https://doi.org/10.1590/s180776922012005000006

Dennis, A. R., Robert, L. P., Curtis, A. M., Kowalczyk, S. T., \& Hasty, B. K. (2012). Research Note: Trust Is in the Eye of the Beholder: A Vignette Study of Postevent Behavioral Controls' Effects on Individual Trust in Virtual Teams. Research, 23(2), 546-558. https://doi.org/10.1287/isre.1110.0364

Dwyer, C., Hiltz, S. R., \& Passerini, K. (2007). Trust and privacy concern within social networking sites: A comparison of Facebook and MySpace. In Association for Information Systems - 13th Americas Conference on Information Systems, AMCIS 2007: Reaching New Heights (Vol. 3, pp. 1725-1735).

Eastlick, M. A., Lotz, S. L., \& Warrington, P. (2006). Understanding online B-to-C relationships: An integrated model of privacy concerns, trust, and commitment. Journal of Business Research, 59(8), 877-886. https://doi.org/10.1016/j.jbusres.2006.02.006

Feng Tian. (2016). An agri-food supply chain traceability system for China based on RFID \&amp; blockchain technology. In 2016 13th International Conference on Service Systems and Service Management (ICSSSM) (pp. 1-6). IEEE. https://doi.org/10.1109/ICSSSM.2016.7538424

Fernandez, E. B., Fonoage, M., VanHilst, M., \& Marta, M. (2008). The secure three-tier architecture pattern. In Proceedings - CISIS 2008: 2nd International Conference on Complex, Intelligent and Software Intensive Systems (pp. 555-560). https://doi.org/10.1109/CISIS.2008.51

Fishbein, M., \& Ajzen, I. (1975). Belief, attitude, intention and behavior: An introduction to theory and research. Addison-Wesley . Reading, MA. Retrieved from http://people.umass.edu/aizen/f\&a1975.html

Folkinshteyn, D., \& Lennon, M. (2016). Braving Bitcoin: A technology acceptance model 
1087

1088

1089

1090

1091

1092

1093

1094

1095

1096

1097

1098

1099

1100

1101

1102

1103

1104

1105

1106

1107

1108

1109

1110

1111

1112

1113

1114

1115

1116

1117

1118

1119

1120

1121

1122

1123

1124

1125

1126

1127

1128

1129

1130

1131

1132

(TAM) analysis. Journal of Information Technology Case and Application Research, 18(4), 220-249. https://doi.org/10.1080/15228053.2016.1275242

Fornell, C., \& Larcker, D. F. (1981). Evaluating Structural Equation Models with Unobservable Variables and Measurement Error. Journal of Marketing Research, 18(1), 39. https://doi.org/10.2307/3151312

Gefen, D. (2000). E-commerce: The role of familiarity and trust. Omega. https://doi.org/10.1016/S0305-0483(00)00021-9

Gefen, Karahanna, \& Straub. (2003). Trust and TAM in Online Shopping: An Integrated Model. MIS Quarterly, 27(1), 51. https://doi.org/10.2307/30036519

Granić, A., \& Marangunić, N. (2019). Technology acceptance model in educational context: A systematic literature review. British Journal of Educational Technology, 50(5), 2572-2593. https://doi.org/10.1111/bjet.12864

Hair, J. F., Hult, G. T. M., Ringle, C. M., \& Sarstedt, M. (2013). A Primer on Partial Least Squares Structural Equation Modeling (PLS-SEM). Sage (Second). Thousand Oaks, California, United States.

Hair, J. F., Black, W. C., Babin, B. J., \& Anderson, R. E. (2014). Multivariate Data Analysis (7th ed.). Pearson Education Limited. Retrieved from www.pearsoned.co.uk

Hoffman, D. L., Novak, T. P., \& Peralta, M. (1999). Building consumer trust online. Communications of the ACM, 42(4), 80-85. https://doi.org/10.1145/299157.299175

Introna, L. D., \& Pouloudi, A. (1999). Privacy in the information age: Stakeholders, interests and values. Journal of Business Ethics, 22(1), 27-38. https://doi.org/10.1023/A:1006151900807

Jarvenpaa, S. L., \& Leidner, D. E. (1999). Communication and Trust in Global Virtual Teams. Organization Science. https://doi.org/10.1287/orsc.10.6.791

Jian, J.-Y., Bisantz, A. M., \& Drury, C. G. (2000). Foundations for an Empirically Determined Scale of Trust in Automated Systems. International Journal of Cognitive Ergonomics, 4(1), 53-71. https://doi.org/10.1207/s15327566ijce0401_04

Jun, M. (2018). Blockchain government - a next form of infrastructure for the twenty-first century. Journal of Open Innovation: Technology, Market, and Complexity, 4(1), 7. https://doi.org/10.1186/s40852-018-0086-3

Kern, A. G. (2018). Blockchain technology : a technology acceptance model (TAM) analysis. Retrieved from http://hdl.handle.net/10400.14/25478

Kim, D. J., Steinfield, C., \& Lai, Y. J. (2008). Revisiting the role of web assurance seals in business-to-consumer electronic commerce. Decision Support Systems. https://doi.org/10.1016/j.dss.2007.11.007

Koh, C. E., Prybutok, V. R., \& Ryan, S. D. (2010). A Model for Mandatory Use of Software Technologies: An Integrative Approach by Applying Multiple Levels of Abstraction of Informing Science. Informing Science: The International Journal of an Emerging Transdiscipline, 13, 177-203. Retrieved from https://pdfs.semanticscholar.org/724c/351bd184d910f24404b53341859e6bcc75d6.pdf

Kshetri, N. (2017). Blockchain's roles in strengthening cybersecurity and protecting privacy. Telecommunications Policy, 41(10), 1027-1038. https://doi.org/10.1016/j.telpol.2017.09.003

Kwong, K., \& Wong, K. (2013). Partial Least Squares Structural Equation Modeling (PLS-SEM) Techniques Using SmartPLS. Marketing Bulletin, 24. Retrieved from http://marketingbulletin.massey.ac.nz

Linck, K., Pousttchi, K., \& Wiedemann, D. G. (2006). Security issues in mobile payment from 
1133

1134

1135

1136

1137

1138

1139

1140

1141

1142

1143

1144

1145

1146

1147

1148

1149

1150

1151

1152

1153

1154

1155

1156

1157

1158

1159

1160

1161

1162

1163

1164

1165

1166

1167

1168

1169

1170

1171

1172

1173

1174

1175

1176

1177

1178

the customer viewpoint. In Proceedings of the 14th European Conference on Information Systems, ECIS 2006.

Liu, I.-F., Chen, M. C., Sun, Y. S., Wible, D., \& Kuo, C.-H. (2010). Extending the TAM model to explore the factors that affect Intention to Use an Online Learning Community. Computers \& Education, 54(2), 600-610. https://doi.org/10.1016/J.COMPEDU.2009.09.009

Malhotra, N. K., Kim, S. S., \& Agarwal, J. (2004). Internet Users' The Information the Scale, and a Causal ( IUIPC ): Informs, 15(4), 336-355. https://doi.org/10.1287/isre.1040.0032

McCole, P., Ramsey, E., \& Williams, J. (2010). Trust considerations on attitudes towards online purchasing: The moderating effect of privacy and security concerns. Journal of Business Research, 63(9-10), 1018-1024. https://doi.org/10.1016/j.jbusres.2009.02.025

McGhin, T., Choo, K. K. R., Liu, C. Z., \& He, D. (2019, June 1). Blockchain in healthcare applications: Research challenges and opportunities. Journal of Network and Computer Applications. Academic Press. https://doi.org/10.1016/j.jnca.2019.02.027

Melas, C. D., Zampetakis, L. A., Dimopoulou, A., \& Moustakis, V. (2011). Modeling the acceptance of clinical information systems among hospital medical staff: An extended TAM model. Journal of Biomedical Informatics, 44(4), 553-564. https://doi.org/10.1016/J.JBI.2011.01.009

Metzger, M. J. (2004). Privacy, trust, and disclosure: Exploring barriers to electronic commerce. Journal of Computer-Mediated Communication. https://doi.org/10.1111/j.10836101.2004.tb00292.x

Muller, K., \& Cohen, J. (1989). Statistical Power Analysis for the Behavioral Sciences. Technometrics. https://doi.org/10.2307/1270020

Nakamoto, S. (2008). Bitcoin: A Peer-to-Peer Electronic Cash System. Retrieved from https://bitcoin.org/bitcoin.pdf

Papadopoulou, P. (2007). Applying virtual reality for trust-building e-commerce environments. Virtual Reality. https://doi.org/10.1007/s10055-006-0059-x

Piccoli, G., \& Ives, B. (2003). Trust and the unintended effects of behavior control in virtual teams. MIS Quarterly: Management Information Systems. https://doi.org/10.2307/30036538

Pikkarainen, T., Pikkarainen, K., Karjaluoto, H., \& Pahnila, S. (2004). Consumer acceptance of online banking: An extension of the technology acceptance model. Internet Research. https://doi.org/10.1108/10662240410542652

Poon, W. C. (2008). Users' adoption of e-banking services: The Malaysian perspective. Journal of Business and Industrial Marketing. https://doi.org/10.1108/08858620810841498

Prashanth Joshi, A., Han, M., \& Wang, Y. (2018). A survey on security and privacy issues of blockchain technology. Mathematical Foundations of Computing, 1(2), 121-147. https://doi.org/10.3934/mfc.2018007

Rios, R., Fernandez-Gago, C., \& Lopez, J. (2017). Modelling privacy-aware trust negotiations. Computers \& Security, 77, 773-789. https://doi.org/10.1016/j.cose.2017.09.015

Roca, J. C., García, J. J., \& de la Vega, J. J. (2009). The importance of perceived trust, security and privacy in online trading systems. Information Management and Computer Security, 17(2), 96-113. https://doi.org/10.1108/09685220910963983

Shin, D. D. H. (2019). Blockchain: The emerging technology of digital trust. Telematics and Informatics, 45, 101278. https://doi.org/10.1016/j.tele.2019.101278

Shin, D. H. (2010). The effects of trust, security and privacy in social networking: A securitybased approach to understand the pattern of adoption. Interacting with Computers, 22(5),

Peer] Comput. Sci. reviewing PDF | (CS-2020:10:53488:1:1:NEW 25 Mar 2021) 
1179

1180

1181

1182

1183

1184

1185

1186

1187

1188

1189

1190

1191

1192

1193

1194

1195

1196

1197

1198

1199

1200

1201

1202

1203

1204

1205

1206

1207

1208

1209

1210

1211

1212

1213

1214

1215

1216

1217

1218

1219

1220

1221

1222

1223

1224

428-438. https://doi.org/10.1016/j.intcom.2010.05.001

Shin, D. H. (2017). Conceptualizing and measuring quality of experience of the internet of things: Exploring how quality is perceived by users. Information and Management, 54(8), 998-1011. https://doi.org/10.1016/j.im.2017.02.006

Shrestha, A. K. (2014). Security of SIP-based infrastructure against malicious message attacks. In The 8th International Conference on Software, Knowledge, Information Management and Applications (SKIMA 2014) (pp. 1-8). Dhaka, Bangladesh: IEEE. https://doi.org/10.1109/SKIMA.2014.7083519

Shrestha, A. K., Deters, R., \& Vassileva, J. (2017). User-Controlled Privacy-Preserving User Profile Data Sharing based on Blockchain. In Future Technologies Conference (FTC) (pp. 31-40). Vancouver, Canada: The Science and Information (SAI) Organization. Retrieved from https://saiconference.com/Downloads/FTC2017/Proceedings/3_Paper_127-UserControlled_Privacy-Preserving_User_Profile_Data_Sharing.pdf

Shrestha, A. K., Joshi, S., \& Vassileva, J. (2020). Customer Data Sharing Platform: A Blockchain-Based Shopping Cart. In IEEE International Conference on Blockchain and Cryptocurrency, ICBC 2020. Institute of Electrical and Electronics Engineers Inc. https://doi.org/10.1109/ICBC48266.2020.9169421

Shrestha, A. K., \& Vassileva, J. (2016). Towards decentralized data storage in general cloud platform for meta-products. Proceedings of the International Conference on Big Data and Advanced Wireless Technologies - BDAW'16, 1-7.

https://doi.org/10.1145/3010089.3016029

Shrestha, A. K., \& Vassileva, J. (2018a). Bitcoin Blockchain Transactions Visualization. In 2018 International Conference on Cloud Computing, Big Data and Blockchain (ICCBB) (pp. 16). Fuzhou, China: IEEE. https://doi.org/10.1109/ICCBB.2018.8756455

Shrestha, A. K., \& Vassileva, J. (2018b). Blockchain-Based Research Data Sharing Framework for Incentivizing the Data Owners. In S. Chen, H. Wang, \& L.-J. Zhang (Eds.), Blockchain - ICBC 2018 (pp. 259-266). Seattle, USA: Springer International Publishing. https://doi.org/10.1007/978-3-319-94478-4_19

Shrestha, A. K., \& Vassileva, J. (2019a). User acceptance of usable blockchain-based research data sharing system: An extended TAM-based study. In Proceedings - 1st IEEE International Conference on Trust, Privacy and Security in Intelligent Systems and Applications, TPS-ISA 2019 (pp. 203-208). Los Angeles: IEEE. https://doi.org/10.1109/TPS-ISA48467.2019.00033

Shrestha, A. K., \& Vassileva, J. (2019b). User Data Sharing Frameworks : A Blockchain-Based Incentive Solution. In The 10th IEEE Annual Information Technology, Electronics and Mobile Communication Conference (IEEE IEMCON 2019). Vancouver, Canada: IEEE.

Shrestha, A. K., Vassileva, J., \& Deters, R. (2020). A Blockchain Platform for User Data Sharing Ensuring User Control and Incentives. Frontiers in Blockchain, 3, 48. https://doi.org/10.3389/FBLOC.2020.497985

Siegel, J., \& Sarma, S. (2019). A Cognitive Protection System for the Internet of Things. IEEE Security and Privacy, 17(3), 40-48. https://doi.org/10.1109/MSEC.2018.2884860

Smith, H. J., Milberg, S. J., \& Burke, S. J. (1996). Information privacy: Measuring individuals' concerns about organizational practices. MIS Quarterly: Management Information Systems, 20(2), 167-195. https://doi.org/10.2307/249477

Swan, M. (2015). Blockchain: Blueprint for a New Economy (First). O'Reilly Media, Inc. Retrieved from https://dl.acm.org/doi/book/10.5555/3006358

Peer) Comput. Sci. reviewing PDF | (CS-2020:10:53488:1:1:NEW 25 Mar 2021) 
1225

1226

1227

1228

1229

1230

1231

1232

1233

1234

1235

1236

1237

1238

1239

1240

1241

1242

1243
Venkatesh, V., Morris, M. G., Davis, G. B., \& Davis, F. D. (2003). User acceptance of information technology: Toward a unified view. MIS Quarterly: Management Information Systems. https://doi.org/10.2307/30036540

Wang, H., Lee, M. K. O., \& Wang, C. (1998). Consumer Privacy Concerns about Internet Marketing. Communications of the ACM. https://doi.org/10.1145/272287.272299

Warren, S. D., \& Brandeis, L. D. (1890). The Right to Privacy. Harvard Law Review (Vol. 4). Retrieved from https://www.jstor.org/stable/1321160

Warshaw, P. R., \& Davis, F. D. (1985). Disentangling behavioral intention and behavioral expectation. Journal of Experimental Social Psychology, 21(3), 213-228. https://doi.org/10.1016/0022-1031(85)90017-4

Westin, A. F. (1968). Privacy And Freedom. Washington and Lee Law Review, 25(1). Retrieved from https://scholarlycommons.law.wlu.edu/wlulr/vol25/iss 1/20

$\mathrm{Wu}$, I.-L., \& Chen, J.-L. (2005). An extension of Trust and TAM model with TPB in the initial adoption of on-line tax: An empirical study. International Journal of Human-Computer Studies, 62(6), 784-808. https://doi.org/10.1016/j.ijhcs.2005.03.003

Yenisey, M. M., Ozok, A. A., \& Salvendy, G. (2005). Perceived security determinants in ecommerce among Turkish university students. Behaviour and Information Technology. https://doi.org/10.1080/0144929042000320992 
Figure 1

Blockchain-Based System of the current study (BBS)

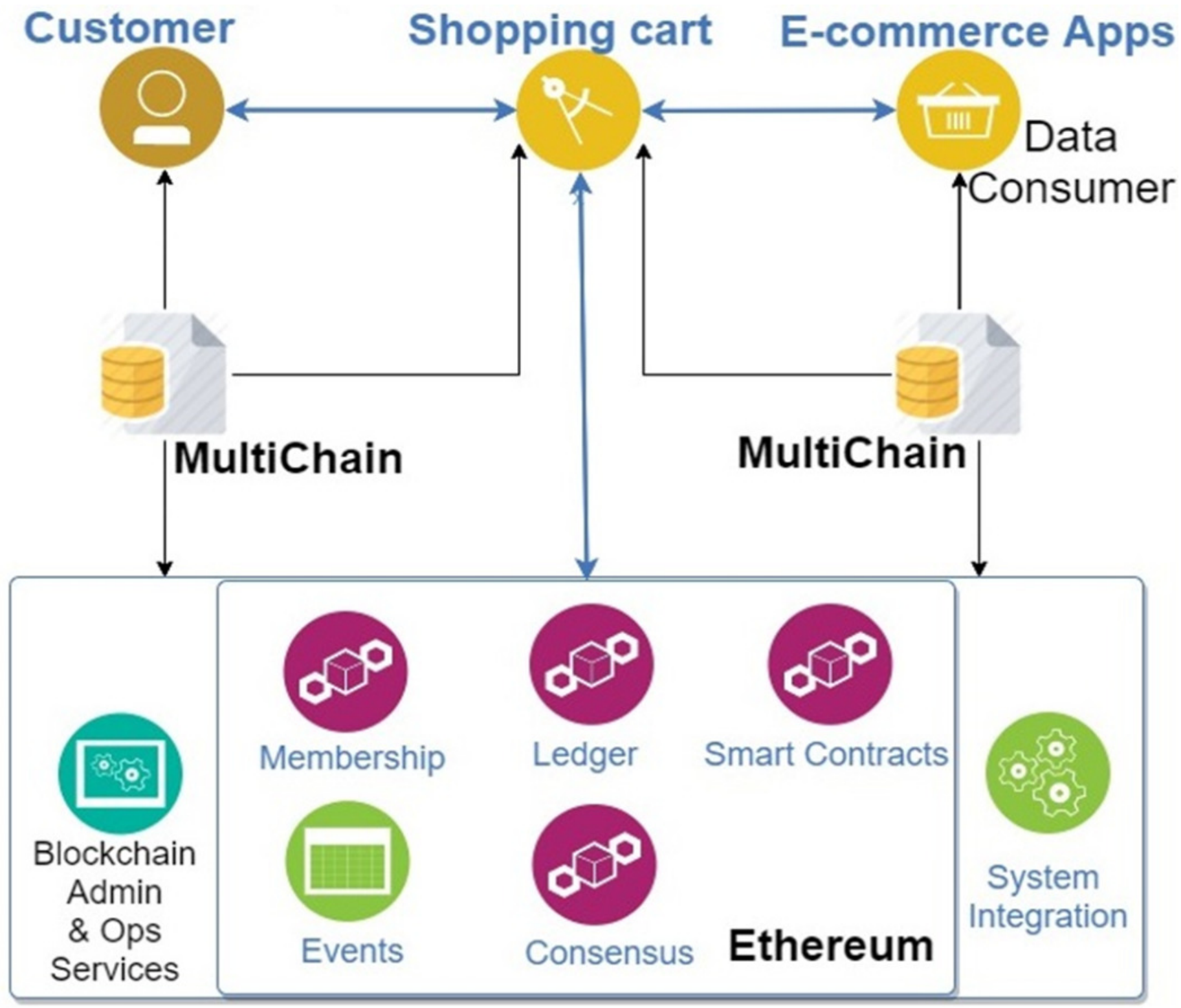


Figure 2

Classical Technology Acceptance Model (TAM)

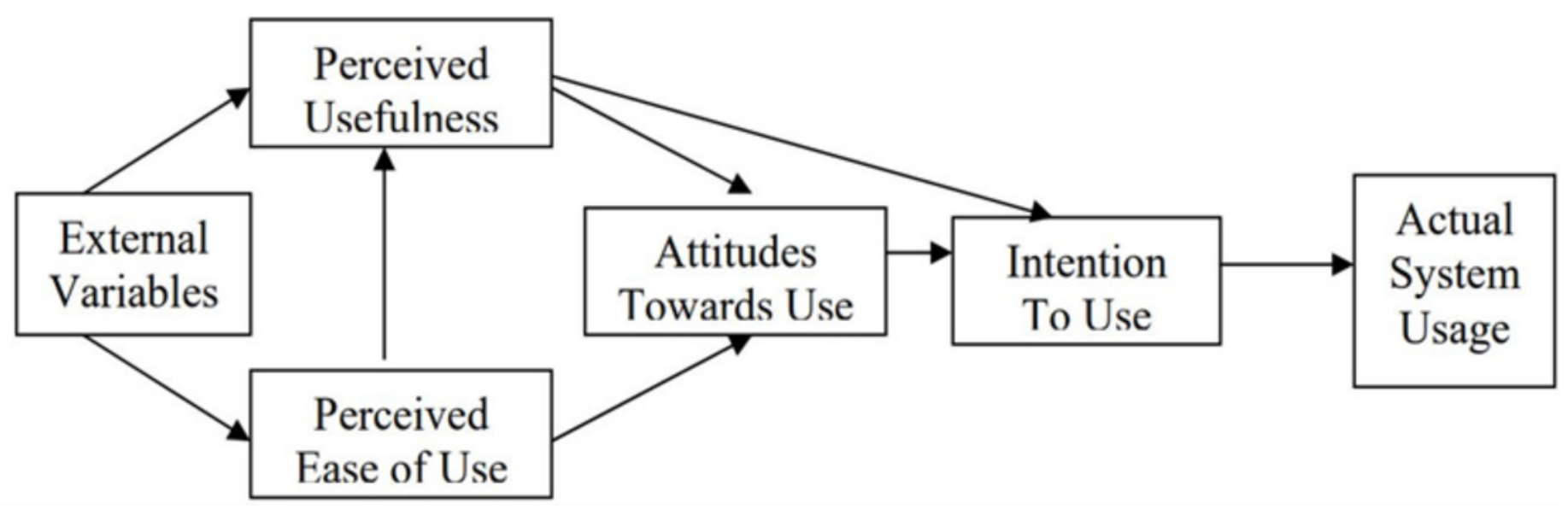


Figure 3

An Augmented TAM with Trust Model

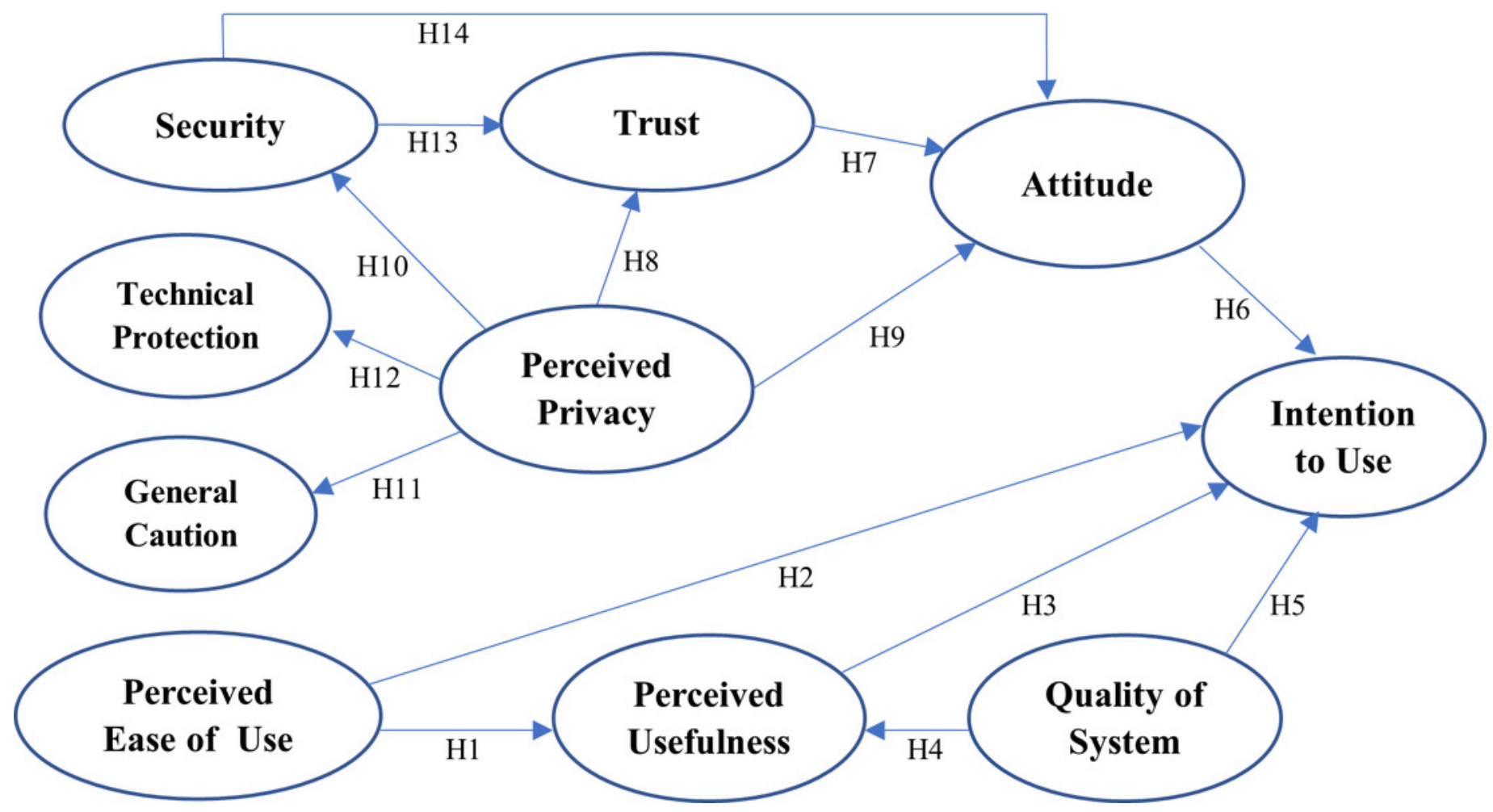


Figure 4

\section{Analysis of constructs}

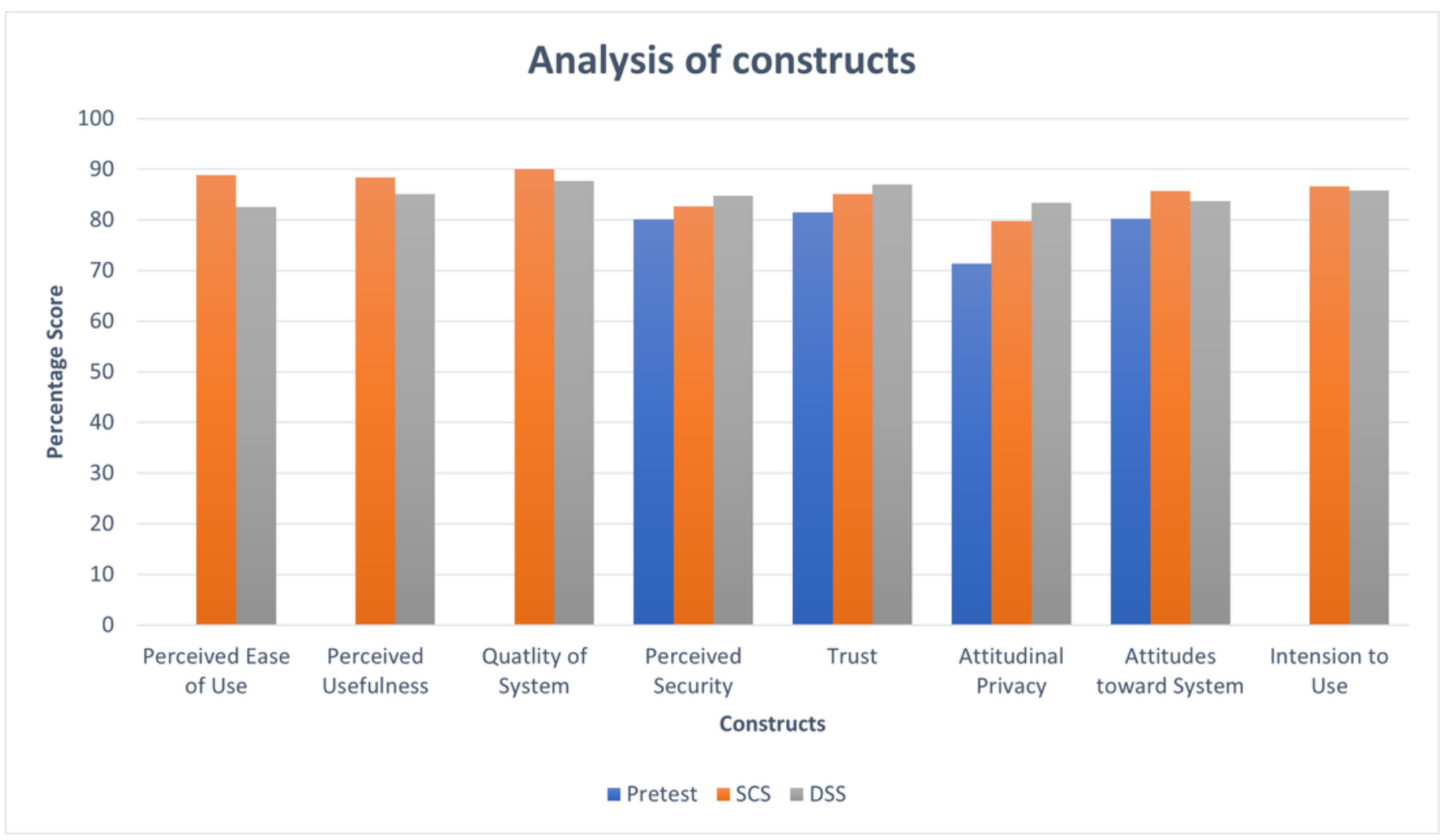


Figure 5

\section{Pretest direct effect}

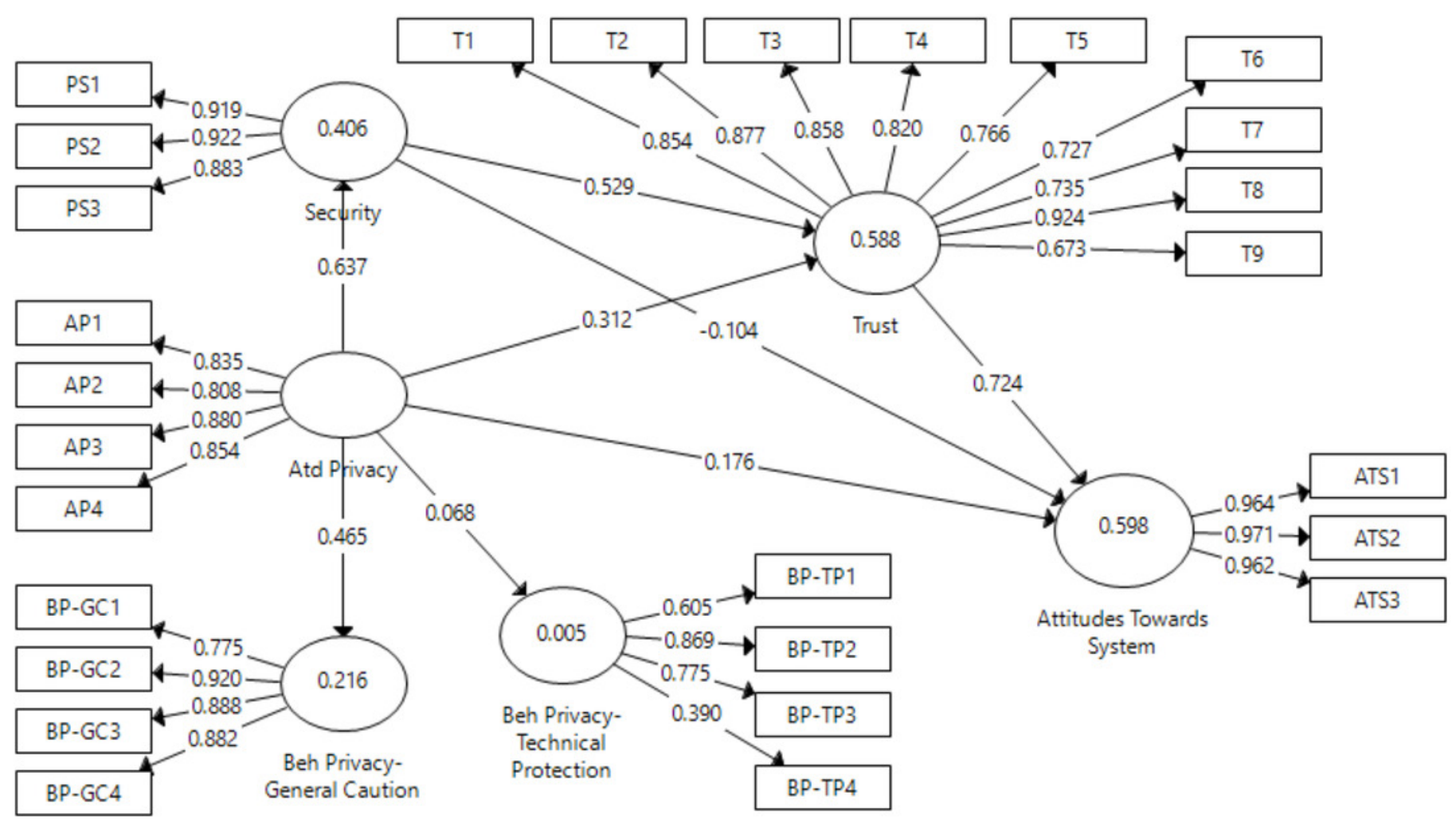


Figure 6

\section{Shopping Cart System (SCS) direct effect}

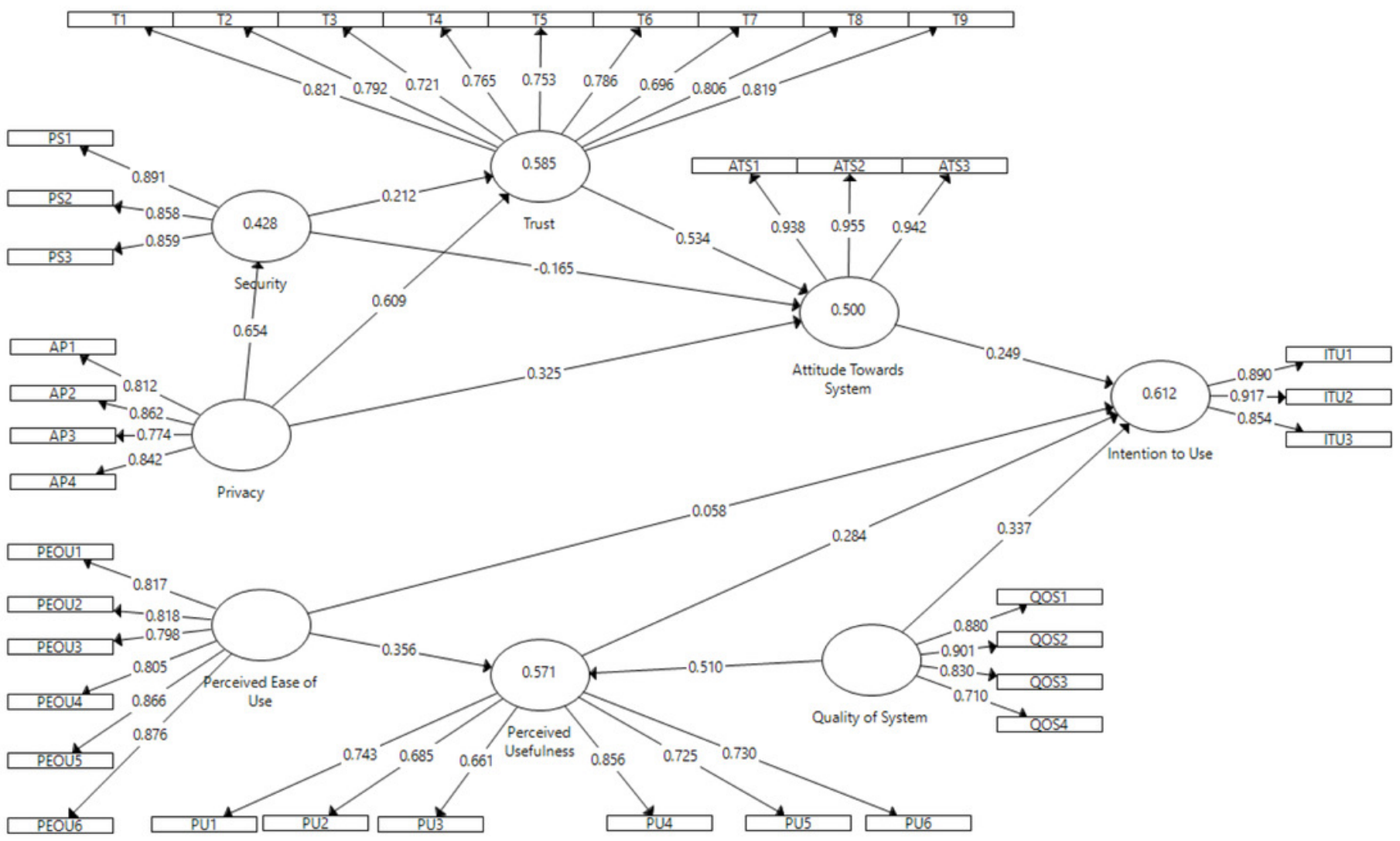


Figure 7

\section{Data Sharing System (DSS) direct effect}

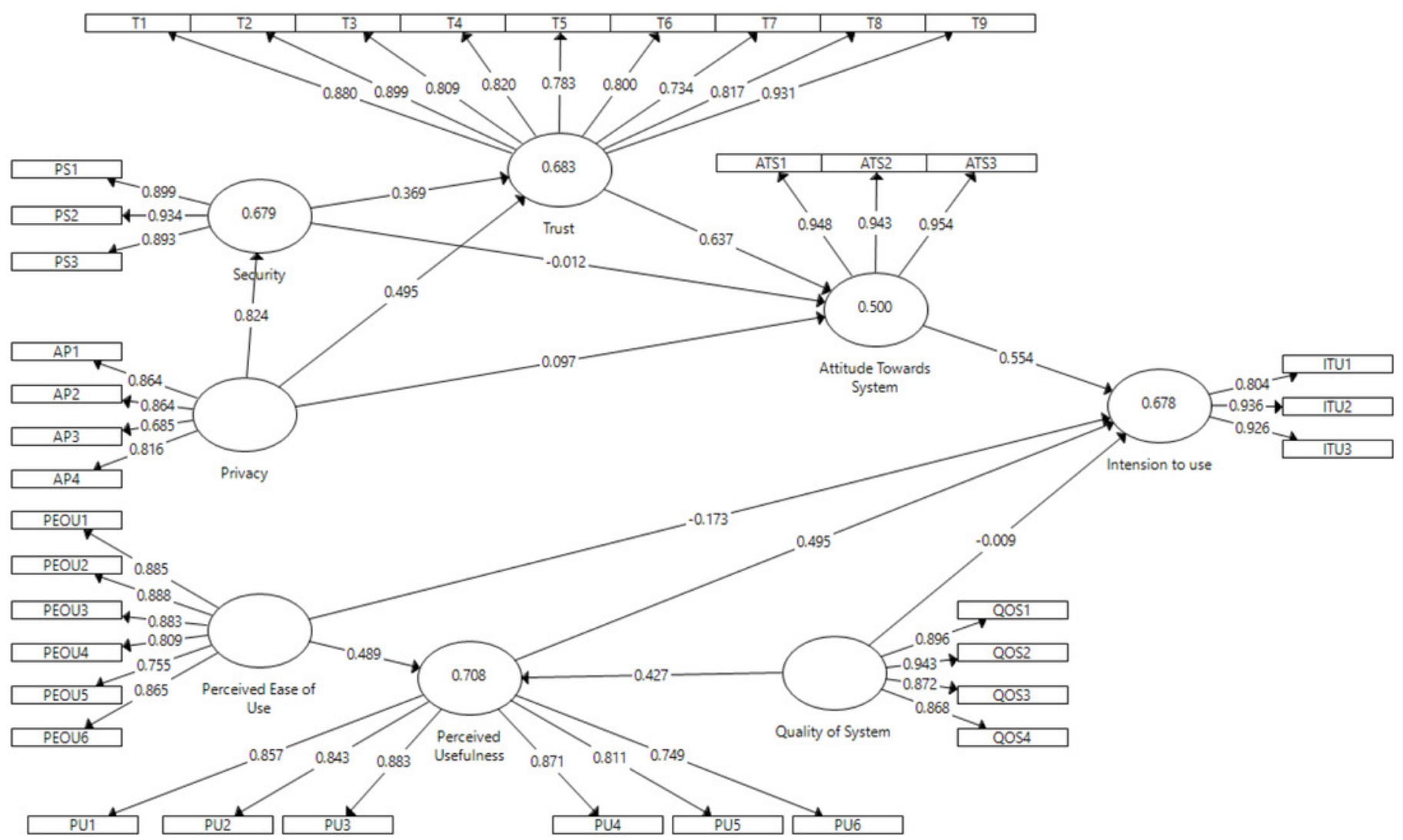


Figure 8

Total effect of the trust design constructs on attitudes towards BBS

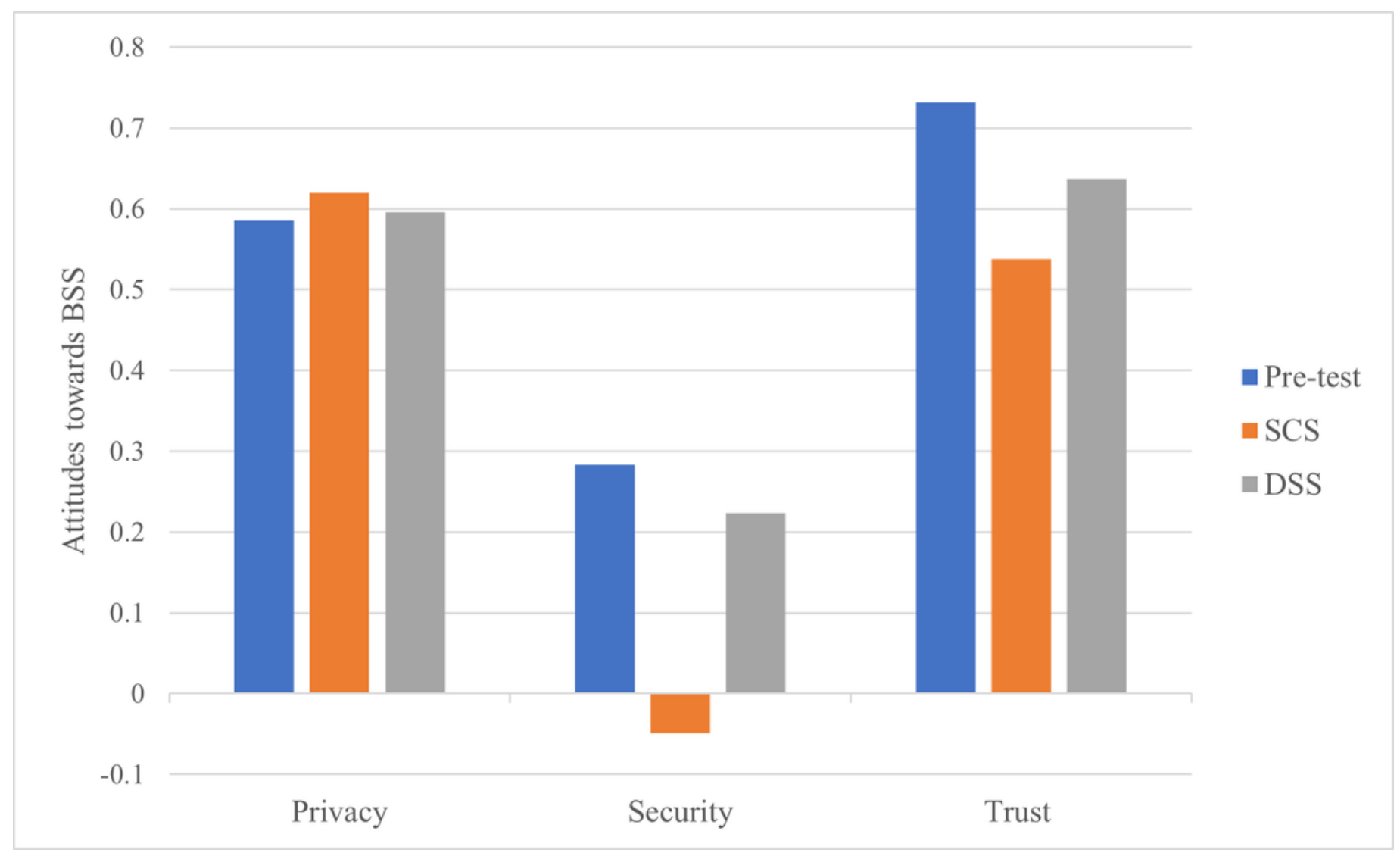


Figure 9

Total effect of predictors on intention to use

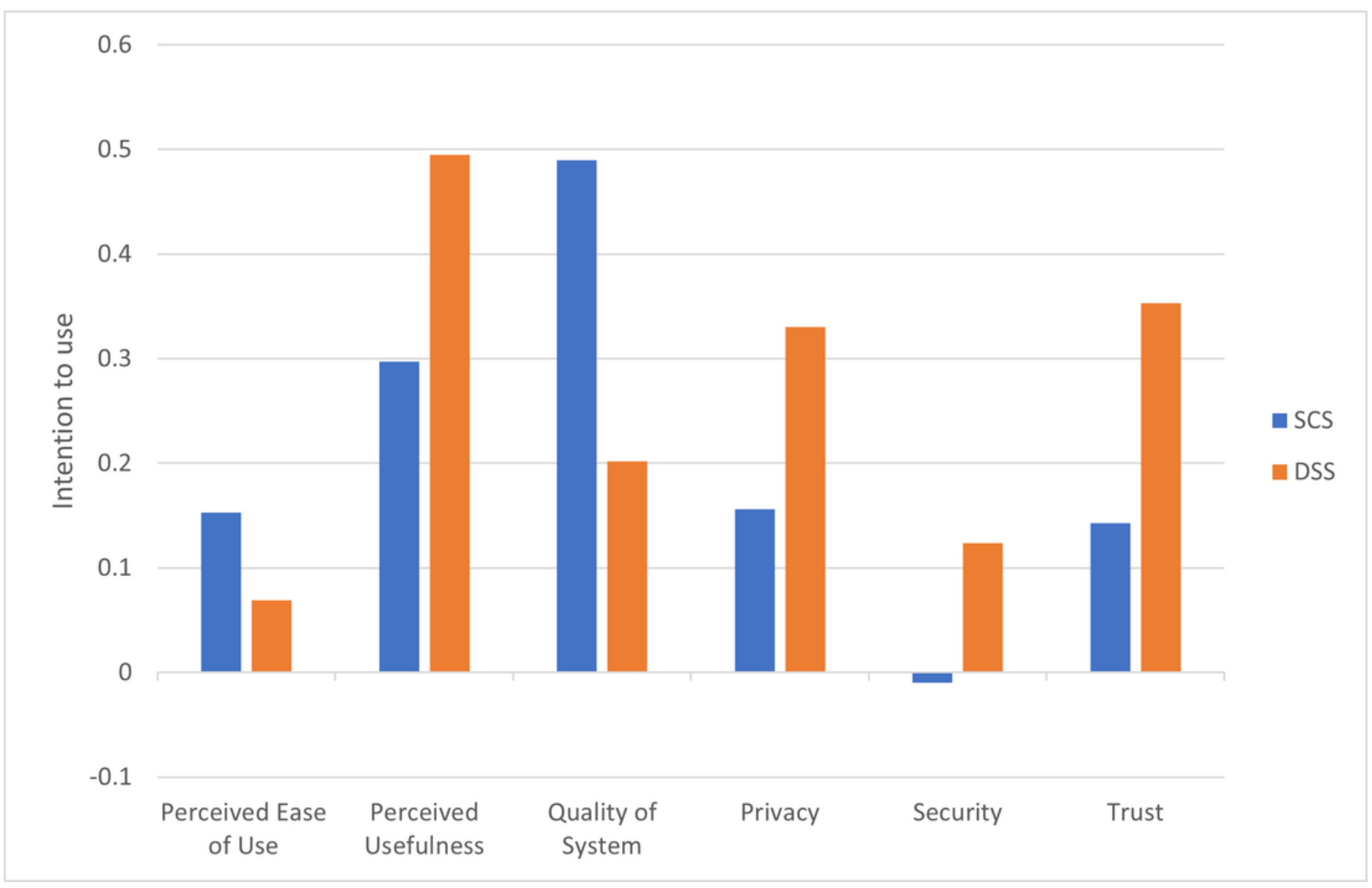




\section{Table $\mathbf{1}$ (on next page)}

Demographics of Participants 


\begin{tabular}{|c|c|c|c|c|c|}
\hline \multirow{2}{*}{ Criterion } & \multirow{2}{*}{ Subgroup } & \multicolumn{2}{|c|}{ Number (\#) } & \multicolumn{2}{|c|}{ Percentage (\%) } \\
\hline & & SCS & DSS & SCS & DSS \\
\hline \multirow{3}{*}{ Gender } & Female & 15 & 11 & 24 & 22 \\
\hline & Male & 48 & 39 & 76 & 78 \\
\hline & Other & 0 & 0 & 0 & 0 \\
\hline \multirow{4}{*}{ Age } & $18-24$ & 6 & 4 & 9.5 & 8 \\
\hline & $25-34$ & 45 & 34 & 71.4 & 68 \\
\hline & $35-44$ & 11 & 9 & 17 & 18 \\
\hline & $44-54$ & 1 & 3 & 1.6 & 6 \\
\hline \multirow{4}{*}{$\begin{array}{l}\text { Highest Education } \\
\text { Completed }\end{array}$} & High school & 1 & 0 & 1.6 & 0 \\
\hline & Bachelors & 13 & 12 & 20.6 & 24 \\
\hline & Masters & 39 & 31 & 61.9 & 62 \\
\hline & $\mathrm{PhD}$ & 10 & 7 & 15.9 & 14 \\
\hline \multirow{4}{*}{ Area } & Business & 2 & 1 & 3.2 & 2 \\
\hline & Comp Sc & 39 & 36 & 61.9 & 72 \\
\hline & Engineering & 20 & 13 & 31.7 & 26 \\
\hline & Social Sc & 2 & 0 & 3.3 & 0 \\
\hline \multirow{6}{*}{ Continent } & Africa & 3 & 2 & 4.8 & 4 \\
\hline & Asia & 30 & 20 & 47.6 & 40 \\
\hline & Europe & 5 & 3 & 7.9 & 6 \\
\hline & N. America & 19 & 18 & 30.2 & 36 \\
\hline & Oceania & 6 & 7 & 9.5 & 14 \\
\hline & S. America & 0 & 0 & 0 & 0 \\
\hline \multirow{7}{*}{$\begin{array}{l}\text { Familiarity with } \\
\text { blockchain and smart } \\
\text { contracts }\end{array}$} & Extremely & 12 & 14 & 19 & 28 \\
\hline & Moderately & 20 & 19 & 31.7 & 38 \\
\hline & Slightly & 30 & 15 & 47.6 & 30 \\
\hline & Neither & 0 & 1 & 0 & 2 \\
\hline & Slightly Not & 1 & 0 & 1.6 & 0 \\
\hline & Moderately Not & 0 & 0 & 0 & 0 \\
\hline & Extremely Not & 0 & 1 & 0 & 2 \\
\hline
\end{tabular}




\section{Table 2 (on next page)}

Exploratory Factor Analysis 


\begin{tabular}{|c|c|c|c|c|}
\hline \multirow{2}{*}{ Construct } & \multirow[b]{2}{*}{ Item } & \multicolumn{3}{|c|}{ Factor Loading } \\
\hline & & Pretest & SCS & DSS \\
\hline \multirow[t]{4}{*}{ Attitudinal Privacy } & AP1 & 0.835 & 0.812 & 0.864 \\
\hline & AP2 & 0.808 & 0.862 & 0.864 \\
\hline & AP3 & 0.88 & 0.774 & 0.685 \\
\hline & AP4 & 0.854 & 0.842 & 0.816 \\
\hline \multirow[t]{3}{*}{ Attitudes Towards System } & ATS1 & 0.964 & 0.938 & 0.948 \\
\hline & ATS2 & 0.971 & 0.955 & 0.943 \\
\hline & ATS3 & 0.962 & 0.942 & 0.954 \\
\hline \multirow[t]{4}{*}{ Beh Privacy-General Caution } & BP-GC1 & 0.775 & & \\
\hline & BP-GC2 & 0.92 & & \\
\hline & BP-GC3 & 0.888 & & \\
\hline & BP-GC4 & 0.882 & & \\
\hline \multirow[t]{4}{*}{ Beh Privacy-Technical Protection } & BP-TP1 & 0.605 & & \\
\hline & BP-TP2 & 0.869 & & \\
\hline & BP-TP3 & 0.775 & & \\
\hline & BP-TP4 & 0.39 & & \\
\hline \multirow[t]{3}{*}{ Security } & PS1 & 0.919 & 0.891 & 0.899 \\
\hline & PS2 & 0.922 & 0.858 & 0.934 \\
\hline & PS3 & 0.883 & 0.859 & 0.893 \\
\hline \multirow[t]{9}{*}{ Trust } & $\mathrm{T} 1$ & 0.854 & 0.821 & 0.88 \\
\hline & $\mathrm{T} 2$ & 0.877 & 0.792 & 0.899 \\
\hline & $\mathrm{T} 3$ & 0.858 & 0.721 & 0.809 \\
\hline & $\mathrm{T} 4$ & 0.82 & 0.765 & 0.82 \\
\hline & T5 & 0.766 & 0.753 & 0.783 \\
\hline & $\mathrm{T} 6$ & 0.727 & 0.786 & 0.8 \\
\hline & $\mathrm{T} 7$ & 0.735 & 0.696 & 0.734 \\
\hline & $\mathrm{T} 8$ & 0.924 & 0.806 & 0.817 \\
\hline & T9 & 0.673 & 0.819 & 0.931 \\
\hline \multirow[t]{3}{*}{ Intention to Use } & ITU1 & & 0.89 & 0.804 \\
\hline & ITU2 & & 0.917 & 0.936 \\
\hline & ITU3 & & 0.854 & 0.926 \\
\hline \multirow[t]{6}{*}{ Perceived Ease of Use } & PEOU1 & & 0.817 & 0.885 \\
\hline & PEOU2 & & 0.818 & 0.888 \\
\hline & PEOU3 & & 0.798 & 0.883 \\
\hline & PEOU4 & & 0.805 & 0.809 \\
\hline & PEOU5 & & 0.866 & 0.755 \\
\hline & PEOU6 & & 0.876 & 0.865 \\
\hline \multirow[t]{6}{*}{ Perceived Usefulness } & PU1 & & 0.743 & 0.857 \\
\hline & PU2 & & 0.685 & 0.843 \\
\hline & PU3 & & 0.661 & 0.883 \\
\hline & PU4 & & 0.856 & 0.871 \\
\hline & PU5 & & 0.725 & 0.811 \\
\hline & PU6 & & 0.73 & 0.749 \\
\hline \multirow[t]{4}{*}{ Quality of System } & QOS1 & & 0.88 & 0.896 \\
\hline & QOS2 & & 0.901 & 0.943 \\
\hline & QOS3 & & 0.83 & 0.872 \\
\hline & QOS4 & & 0.71 & 0.868 \\
\hline
\end{tabular}




\section{Table $\mathbf{3}$ (on next page)}

Constructs Reliability and Validity 


\begin{tabular}{|l|l|l|l|l|l|l|l|l|l|}
\hline & \multicolumn{3}{|c|}{ Pretest } & \multicolumn{3}{c|}{ SCS } & \multicolumn{3}{c|}{ DSS } \\
\hline Construct & rho_A & CR & AVE & rho_A & CR & AVE & rho_A & CR & AVE \\
\hline Attitudes Towards System & 0.967 & 0.976 & 0.932 & 0.94 & 0.962 & 0.893 & 0.944 & 0.964 & 0.899 \\
\hline Intention to Use & $\mathrm{X}$ & $\mathrm{X}$ & $\mathrm{X}$ & 0.873 & 0.917 & 0.787 & 0.875 & 0.92 & 0.794 \\
\hline Perceived Ease of Use & $\mathrm{X}$ & $\mathrm{X}$ & $\mathrm{X}$ & 0.923 & 0.93 & 0.69 & 0.928 & 0.939 & 0.721 \\
\hline Perceived Usefulness & $\mathrm{X}$ & $\mathrm{X}$ & $\mathrm{X}$ & 0.834 & 0.876 & 0.541 & 0.917 & 0.933 & 0.7 \\
\hline Atd Privacy or Privacy & 0.875 & 0.909 & 0.714 & 0.843 & 0.894 & 0.678 & 0.838 & 0.884 & 0.657 \\
\hline Quality of System & $\mathrm{X}$ & $\mathrm{X}$ & $\mathrm{X}$ & 0.872 & 0.9 & 0.695 & 0.928 & 0.942 & 0.801 \\
\hline Security & 0.894 & 0.934 & 0.825 & 0.84 & 0.903 & 0.756 & 0.895 & 0.935 & 0.826 \\
\hline Trust & 0.942 & 0.944 & 0.652 & 0.919 & 0.931 & 0.599 & 0.948 & 0.953 & 0.693 \\
\hline Beh Privacy-General Caution & 0.93 & 0.924 & 0.753 & $\mathrm{X}$ & $\mathrm{X}$ & $\mathrm{X}$ & $\mathrm{X}$ & $\mathrm{X}$ & $\mathrm{X}$ \\
\hline Beh Privacy-Technical Protection & 0.285 & 0.766 & 0.469 & $\mathrm{X}$ & $\mathrm{X}$ & $\mathrm{X}$ & $\mathrm{X}$ & $\mathrm{X}$ & $\mathrm{X}$ \\
\hline
\end{tabular}

1 


\section{Table 4(on next page)}

Discriminant Validity 


\begin{tabular}{|c|c|c|c|c|c|c|c|c|}
\hline \multicolumn{9}{|c|}{ Pretest } \\
\hline Construct & \multicolumn{2}{|l|}{ AP } & ATS & \multicolumn{2}{|c|}{ BP-GC } & BP-TP & $\mathbf{S}$ & $T$ \\
\hline Atd Privacy & \multicolumn{2}{|l|}{0.845} & \multirow[b]{2}{*}{0.965} & & & & & \\
\hline Attitudes Toward BSS & \multicolumn{2}{|l|}{0.58} & & & & & & \\
\hline Beh Privacy-General Caution & \multicolumn{2}{|l|}{0.465} & 0.285 & \multicolumn{2}{|l|}{0.868} & & & \\
\hline Beh Privacy-Technical Protection & \multicolumn{2}{|l|}{0.068} & 0.187 & \multicolumn{2}{|l|}{0.375} & 0.684 & & \\
\hline Security & \multicolumn{2}{|l|}{0.637} & 0.535 & \multicolumn{2}{|l|}{0.303} & -0.065 & 0.908 & \\
\hline Trust & 0.65 & & 0.762 & \multicolumn{2}{|l|}{0.275} & 0.162 & 0.728 & 0.808 \\
\hline \multicolumn{9}{|c|}{ Shopping Cart System (SCS) } \\
\hline & ATS & ITU & \begin{tabular}{l|l} 
PEOU \\
\end{tabular} & $\mathbf{P U}$ & $\mathbf{P}$ & QOS & $\mathbf{S}$ & $\mathbf{T}$ \\
\hline Attitudes Toward SCS & 0.945 & & & & & & & \\
\hline Intention to Use & 0.61 & 0.887 & & & & & & \\
\hline Perceived Ease of Use & 0.557 & 0.543 & 0.831 & & & & & \\
\hline Perceived Usefulness & 0.553 & 0.691 & 0.615 & 0.736 & & & & \\
\hline Privacy & 0.617 & 0.587 & 0.482 & 0.489 & 0.823 & & & \\
\hline Quality of System & 0.509 & 0.69 & 0.508 & 0.691 & 0.299 & 0.834 & & \\
\hline Security & 0.374 & 0.398 & 0.233 & 0.344 & 0.654 & 0.282 & 0.87 & \\
\hline Trust & 0.677 & 0.653 & 0.599 & 0.56 & 0.748 & 0.395 & 0.61 & 0.774 \\
\hline \multicolumn{9}{|c|}{ Data Sharing System (DCS) } \\
\hline & ATS & ITU & PEOU & PU & $\mathbf{P}$ & QOS & $\mathbf{S}$ & $T$ \\
\hline Attitude Towards DSS & 0.948 & & & & & & & \\
\hline Intension to use & 0.766 & 0.891 & & & & & & \\
\hline Perceived Ease of Use & 0.661 & 0.573 & 0.849 & & & & & \\
\hline Perceived Usefulness & 0.672 & 0.725 & 0.782 & $\mathbf{0 . 8 3 7}$ & & & & \\
\hline Privacy & 0.596 & 0.496 & 0.666 & 0.656 & 0.81 & & & \\
\hline Quality of System & 0.688 & 0.631 & 0.685 & 0.762 & 0.708 & 0.895 & & \\
\hline Security & 0.563 & 0.447 & 0.592 & 0.68 & 0.824 & 0.7 & 0.909 & \\
\hline Trust & 0.705 & 0.557 & 0.718 & 0.713 & 0.8 & 0.775 & 0.777 & 0.832 \\
\hline
\end{tabular}




\section{Table 5 (on next page)}

Structural estimates (hypotheses testing) for Pre-test

Direct effect column is when all latent variables are present in the model without any exclusion $* * * p<0.001, * * p<0.01, * p<0.05$

$R^{2}$ (Attitude $=0.598 ; B P-G C=0.216 ; B P-T P=0.005 ;$ Security $=0.406 ;$ Trust $=0.588$ ) 


\begin{tabular}{|l|l|l|l|l|l|l|l|l|l|l|}
\hline \multirow{2}{*}{ Structural Path } & \multicolumn{3}{|c|}{ Direct effect } & \multicolumn{3}{c|}{ Total effect } & \multicolumn{3}{|c|}{ Indirect effect } \\
\cline { 2 - 11 } & Std $\boldsymbol{\beta}$ & $\mathbf{T}$ & $\mathbf{P}$ & Std $\boldsymbol{\beta}$ & $\mathbf{T}$ & $\mathbf{P}$ & Std $\boldsymbol{\beta}$ & T & P & VAF \\
\hline $\begin{array}{l}\text { Atd Privacy } \rightarrow \text { Attitudes } \\
\text { Towards System }\end{array}$ & 0.176 & 1.4 & 0.162 & 0.586 & 6.403 & 0 & 0.412 & 4.466 & 0 & 0.703 \\
\hline $\begin{array}{l}\text { Atd Privacy } \rightarrow \text { Beh } \\
\text { Privacy-General Caution }\end{array}$ & 0.465 & 5.123 & 0 & 0.474 & 5.123 & 0 & & & & \\
\hline $\begin{array}{l}\text { Atd Privacy } \rightarrow \text { Beh } \\
\text { Privacy-Tech Protection }\end{array}$ & 0.068 & 0.366 & 0.715 & 0.036 & 0.366 & 0.715 & & & & \\
\hline Atd Privacy $\rightarrow$ Security & 0.64 & 9.94 & 0 & 0.64 & 9.94 & 0 & & & & \\
\hline Atd Privacy $\rightarrow$ Trust & 0.313 & 3.8 & 0 & 0.654 & 10.921 & 0 & 0.341 & 5.301 & 0 & 0.521 \\
\hline $\begin{array}{l}\text { Security } \rightarrow \text { Attitudes } \\
\text { Towards System }\end{array}$ & -0.104 & 0.865 & 0.387 & 0.283 & 2.396 & 0.017 & 0.391 & 4.348 & 0 & 1.382 \\
\hline Security $\rightarrow$ Trust & 0.529 & 6.446 & 0 & 0.529 & 6.446 & 0 & & & & \\
\hline $\begin{array}{l}\text { Trust } \rightarrow \text { Attitudes Towards } \\
\text { System }\end{array}$ & 0.724 & 6.33 & 0 & 0.732 & 6.33 & 0 & & & & \\
\hline
\end{tabular}

1 


\section{Table 6(on next page)}

Structural estimates (hypotheses testing) for SCS

Direct effect column is when all latent variables are present in the model without any exclusion $* * * p<0.001, * * p<0.01, * p<0.1$

$R^{2}$ (Attitude $=0.5 ;$ Intention $=0.612 ;$ Perceived Usefulness $=0.571$; Security $=0.428 ;$ Trust $=0.585$ ) 


\begin{tabular}{|l|l|l|l|l|l|l|l|l|l|l|}
\hline \multirow{2}{*}{ Structural Path } & \multicolumn{3}{|c|}{ Direct effect } & \multicolumn{3}{c|}{ Total effect } & \multicolumn{3}{c|}{ Indirect effect } \\
\cline { 2 - 11 } & Std $\boldsymbol{\beta}$ & $\mathbf{T}$ & $\mathbf{P}$ & Std $\boldsymbol{\beta}$ & $\mathbf{T}$ & $\mathbf{P}$ & Std $\boldsymbol{\beta}$ & T & P & VAF \\
\hline $\begin{array}{l}\text { Attitude Towards System } \rightarrow \\
\text { Intention to Use }\end{array}$ & 0.25 & 1.713 & 0.087 & 0.25 & 1.713 & 0.087 & & & & \\
\hline $\begin{array}{l}\text { Perceived Ease of Use } \rightarrow \\
\text { Intention to Use }\end{array}$ & 0.058 & 0.449 & 0.653 & 0.153 & 1.201 & 0.23 & 0.108 & 1.363 & 0.173 & 0.706 \\
\hline $\begin{array}{l}\text { Perceived Ease of Use } \rightarrow \\
\text { Perceived Usefulness }\end{array}$ & 0.356 & 2.902 & 0.004 & 0.362 & 2.902 & 0.004 & & & & \\
\hline $\begin{array}{l}\text { Perceived Usefulness } \rightarrow \\
\text { Intention to Use }\end{array}$ & 0.284 & 1.743 & 0.081 & 0.297 & 1.743 & 0.081 & & & & \\
\hline $\begin{array}{l}\text { Privacy } \rightarrow \text { Attitude Towards } \\
\text { SCS }\end{array}$ & 0.325 & 2.828 & 0.005 & 0.62 & 7.626 & 0 & 0.293 & 2.23 & 0.026 & 0.473 \\
\hline Privacy $\rightarrow$ Security & 0.654 & 8.333 & 0 & 0.664 & 8.333 & 0 & & & & \\
\hline Privacy $\rightarrow$ Trust & 0.597 & 4.58 & 0 & 0.752 & 11.855 & 0 & 0.155 & 1.225 & 0.221 & 0.206 \\
\hline $\begin{array}{l}\text { Quality of System } \rightarrow \text { Intention } \\
\text { to Use }\end{array}$ & 0.338 & 2.116 & 0.034 & 0.49 & 4.116 & 0 & 0.152 & 1.557 & 0.12 & 0.31 \\
\hline $\begin{array}{l}\text { Quality of System } \rightarrow \\
\text { Perceived Usefulness }\end{array}$ & 0.509 & 4.731 & 0 & 0.509 & 4.731 & 0 & & & & \\
\hline $\begin{array}{l}\text { Security } \rightarrow \text { Attitude Towards } \\
\text { SCS }\end{array}$ & -0.165 & 1.536 & 0.125 & -0.049 & 0.349 & 0.727 & 0.122 & 1.191 & 0.234 & -2.489 \\
\hline Security $\rightarrow$ Trust & 0.212 & 1.339 & 0.181 & 0.229 & 1.339 & 0.181 & & & & \\
\hline $\begin{array}{l}\text { Trust } \rightarrow \text { Attitude Towards } \\
\text { SCS }\end{array}$ & 0.534 & 3.349 & 0.001 & 0.538 & 3.349 & 0.001 & & & & \\
\hline
\end{tabular}




\section{Table 7 (on next page)}

Structural estimates (hypotheses testing) for DSS

Direct effect column is when all latent variables are present in the model without any exclusion ${ }^{* * * p}<0.001, * * p<0.01, * p<0.1$

$R^{2}$ (Attitude $=0.5$; Intension to use $=0.678 ;$ Perceived Usefulness $=0.708 ;$ Security $=0.679 ;$ Trust $=0.683$ ) 


\begin{tabular}{|l|l|l|l|l|l|l|l|l|l|l|}
\hline \multirow{2}{*}{ Structural Path } & \multicolumn{3}{|c|}{ Direct effect } & \multicolumn{3}{c|}{ Total effect } & \multicolumn{3}{c|}{ Indirect effect } & \\
\cline { 2 - 11 } & Std $\boldsymbol{\beta}$ & $\mathbf{T}$ & $\mathbf{P}$ & Std $\boldsymbol{\beta}$ & $\mathbf{T}$ & $\mathbf{P}$ & Std $\boldsymbol{\beta}$ & $\mathbf{T}$ & $\mathbf{P}$ & VAF \\
\hline $\begin{array}{l}\text { Attitude Towards System } \\
\rightarrow \text { Intention to Use }\end{array}$ & 0.554 & 3.967 & 0 & 0.554 & 3.967 & 0 & & & & \\
\hline $\begin{array}{l}\text { Perceived Ease of Use } \rightarrow \\
\text { Intention to Use }\end{array}$ & -0.173 & 0.979 & 0.327 & 0.069 & 0.5 & 0.617 & 0.242 & 1.946 & 0.052 & 3.507 \\
\hline $\begin{array}{l}\text { Perceived Ease of Use } \rightarrow \\
\text { Perceived Usefulness }\end{array}$ & 0.488 & 3.456 & 0.001 & 0.489 & 3.456 & 0.001 & & & & \\
\hline $\begin{array}{l}\text { Perceived Usefulness } \rightarrow \\
\text { Intention to Use }\end{array}$ & 0.495 & 2.354 & 0.019 & 0.495 & 2.354 & 0.019 & & & & \\
\hline $\begin{array}{l}\text { Privacy } \rightarrow \text { Attitude } \\
\text { Towards System }\end{array}$ & 0.097 & 0.383 & 0.701 & 0.596 & 5.531 & 0 & 0.5 & 2.319 & 0.02 & 0.839 \\
\hline Privacy $\rightarrow$ Security & 0.82 & 15.161 & 0 & 0.824 & 15.161 & 0 & & & & \\
\hline Privacy $\rightarrow$ Trust & 0.495 & 3.54 & 0 & 0.8 & 14.958 & 0 & 0.304 & 2.59 & 0.01 & 0.38 \\
\hline $\begin{array}{l}\text { Quality of System } \\
\rightarrow \text { Intention to Use }\end{array}$ & -0.009 & 0.046 & 0.964 & 0.202 & 1.063 & 0.288 & 0.212 & 1.846 & 0.065 & 1.05 \\
\hline $\begin{array}{l}\text { Quality of System } \rightarrow \\
\text { Perceived Usefulness }\end{array}$ & 0.427 & 2.667 & 0.008 & 0.427 & 2.667 & 0.008 & & & & \\
\hline $\begin{array}{l}\text { Security } \rightarrow \text { Attitude } \\
\text { Towards System }\end{array}$ & -0.012 & 0.053 & 0.958 & 0.223 & 0.998 & 0.318 & 0.235 & 2.113 & 0.035 & 1.05 \\
\hline Security $\rightarrow$ Trust & 0.369 & 2.566 & 0.01 & 0.369 & 2.566 & 0.01 & & & & \\
\hline $\begin{array}{l}\text { Trust } \rightarrow \text { Attitude } \\
\text { Towards System }\end{array}$ & 0.637 & 4.316 & 0 & 0.637 & 4.316 & 0 & & & & \\
\hline
\end{tabular}




\section{Table 8 (on next page)}

Validation of the study's hypotheses

$\sqrt{ }=$ True; $x=$ False; $\sqrt{ }->=$ Mediated by latent variable; $x->=$ Not mediated by latent variable 


\begin{tabular}{|c|c|c|c|c|}
\hline & Hypothesis & Pre-test & SCS & DDS \\
\hline H1 & $\begin{array}{l}\text { Perceived ease of use significantly influences } \\
\text { perceived usefulness of BBS. }\end{array}$ & & $\sqrt{ }$ & $\sqrt{ }$ \\
\hline H2 & $\begin{array}{l}\text { Perceived ease of use significantly influences } \\
\text { intention to use BBS. }\end{array}$ & & $\begin{array}{l}\times \\
(\times \rightarrow \text { Usefulness })\end{array}$ & $\begin{array}{l}X \\
(\sqrt{ } \rightarrow \text { Usefulness })\end{array}$ \\
\hline H3 & $\begin{array}{l}\text { Perceived usefulness significantly influences } \\
\text { intention to use BBS. }\end{array}$ & & $\sqrt{ }$ & $\sqrt{ }$ \\
\hline H4 & $\begin{array}{l}\text { Quality of system significantly influences } \\
\text { perceived usefulness of BBS. }\end{array}$ & & $\sqrt{ }$ & $\sqrt{ }$ \\
\hline H5 & $\begin{array}{l}\text { Quality of system significantly influences } \\
\text { intention to use BBS. }\end{array}$ & & $\begin{array}{l}\sqrt{(\times \rightarrow \text { Usefulness })} \\
(x)\end{array}$ & $\begin{array}{l}X \\
(\sqrt{ } \rightarrow \text { Usefulness })\end{array}$ \\
\hline H6 & $\begin{array}{l}\text { Attitude towards BBS significantly influences } \\
\text { intention to use BBS. }\end{array}$ & & $\sqrt{ }$ & $\sqrt{ }$ \\
\hline H7 & $\begin{array}{l}\text { Trust positively affects users' attitudes toward } \\
\text { BBS. }\end{array}$ & $\sqrt{ }$ & $\sqrt{ }$ & $\sqrt{ }$ \\
\hline H8 & $\begin{array}{l}\text { Perceived privacy has a positive effect on the } \\
\text { users' trust in BBS. }\end{array}$ & $\sqrt{ }$ & $\sqrt{ }$ & $\sqrt{ }$ \\
\hline H9 & $\begin{array}{l}\text { Perceived privacy has a positive effect on the } \\
\text { users' attitudes toward BBS. }\end{array}$ & $\begin{array}{l}\times \\
(\sqrt{ } \rightarrow \text { Trust }) \\
(\times \rightarrow \text { Security })\end{array}$ & $\begin{array}{l}\sqrt{ } \\
(\sqrt{ } \rightarrow \text { Trust }) \\
(\times \rightarrow \text { Security })\end{array}$ & $\begin{array}{l}\times \\
(\sqrt{ } \rightarrow \text { Trust }) \\
(\times \rightarrow \text { Security })\end{array}$ \\
\hline H10 & $\begin{array}{l}\text { Perceived privacy positively or negatively affects } \\
\text { users' perceived security. }\end{array}$ & $\sqrt{ }$ & $\sqrt{ }$ & $\sqrt{ }$ \\
\hline H11 & $\begin{array}{l}\text { Privacy concern positively affects users' behavior } \\
\text { on general caution. }\end{array}$ & $\sqrt{ }$ & & \\
\hline H12 & $\begin{array}{l}\text { Privacy concern positively affects users' behavior } \\
\text { on technical protection. }\end{array}$ & $x$ & & \\
\hline H13 & $\begin{array}{l}\text { Perceived security positively affects users' trust } \\
\text { in BBS. }\end{array}$ & $\sqrt{ }$ & $x$ & $\sqrt{ }$ \\
\hline H14 & $\begin{array}{l}\text { Perceived security positively affects users' } \\
\text { attitudes toward BBS. }\end{array}$ & $\begin{array}{l}X \\
(\sqrt{ } \rightarrow \text { Trust })\end{array}$ & $\begin{array}{l}\times \\
(\times \rightarrow \text { Trust })\end{array}$ & $\begin{array}{l}\times \\
(\times \rightarrow \text { Trust })\end{array}$ \\
\hline
\end{tabular}

